\title{
AIAA
}

\section{THREE-DIMENSIONAL EFFECTS IN THE PLATE ELEMENT ANALYSIS OF STITCHED TEXTILE COMPOSITES}

\author{
E. H. Glaessgen and I. S. Raju
}

NASA Langley Research Center

Hampton, Virginia

AIAA Paper No. 99-1416

Presented at the 40th AIAA/ASME/ASCE/AHS/ASC Structures, Structural Dynamics, and Materials Conference and Exhibit

St. Louis, Missouri

April 12-15, 1999 


\title{
THREE-DIMENSIONAL EFFECTS IN THE PLATE ELEMENT ANALYSIS OF STITCHED TEXTILE COMPOSITES
}

\author{
E.H. Glaessgen ${ }^{*}$ and I.S. Raju ${ }^{\dagger}$ \\ NASA Langley Research Center, Hampton, VA 23681-0001, U.S.A.
}

\begin{abstract}
Three-dimensional effects related to the analysis of stitched textile composites are discussed. The method of calculation is based on the virtual crack closure technique (VCCT), and models that model the upper and lower surface of the delamination or debond with two-dimensional (2D) plate elements rather than threedimensional (3D) solid elements. The major advantages of the plate element modeling technique are a smaller model size and simpler geometric modeling. Details of the modeling of the laminated plate and the stitching are discussed.
\end{abstract}

\section{Introduction}

Stitched warp-knit textile composite materials are currently being considered for use in primary aircraft structures. Stitched composite wing skins are being developed to demonstrate both the manufacturing and analytical technology needed to produce such structures. ${ }^{\prime}$ Structural panels, such as the one shown in Figure 1(a), consist of skin, stiffeners, and intercostals. These panels are typically made of between two and ten stacks of 0.055 in. thick carbon warp-knit fabric that are layered and stitched with Kevlar yarns to form the skin. The stiffeners and intercostals are made of a similar number of stacks of layered and stitched fabric and are then stitched to the skin. Once the preform is assembled, the entire structure is infused with epoxy resin.

Skin-stiffener debonding is a critical failure mode for such stiffened composite panels. Fracture mechanics approaches utilizing the concept of strain energy release rate have been used to predict the growth of skin-stiffener debonds with considerable success. ${ }^{2-4}$

Stitching the skin to the stiffeners and intercostals may suppress growth of the debonds by effectively reducing the debond opening and hence the strain energy release rates at the debond front. The effects of

\footnotetext{
* Research Associate, National Research Council, Member AIAA † Head, Mechanics of Materials Branch, Associate Fellow AIAA

Copyright 1999 by the American Institute of Aeronautics and Astronautics, Inc. No copyright is asserted in the United States under Title 17, U.S. Code. The U.S. Government has a royalty-free license to exercise all rights under the copyright claimed herein for Governmental Purposes. All other rights are reserved by the copyright owner.
}

stitching on delamination or debond growth in composites have been examined in simple configurations with some success. ${ }^{5-12}$ In these works, the stitches are modeled as truss or beam elements connecting nodes through the thickness of the material. References 5-10 modeled laminates as twodimensional plane strain structural components, while references 11-12 modeled the laminates as threedimensional solids. An advantage of the threedimensional modeling is to allow the stitches to be modeled discretely rather than as structural components with an "effective" stiffness.

Both plane strain and three-dimensional finite element analyses have been used to study edge debonding and near-surface debonding of unstitched composites. ${ }^{2-4}$ Finite element analysis using plate elements to model the configuration and nonlinear spring elements to model the stitches have been implemented to evaluate strain energy release rates for debonds at the skinstiffener interface. ${ }^{13-14}$ These models require many fewer degrees of freedom than are needed for the full 3D analyses. $^{15-18}$ These plate element models, in conjunction with the virtual crack closure technique (VCCT), were used to evaluate the values for mode I and mode II strain energy release rates. The accuracy of the analyses using plate element models needs to be evaluated by analyses using 3D models.

The objective of this paper is to perform threedimensional modeling of the stitched skin-stiffened structures with debonds and evaluate the accuracy of the techniques used to model debonding of the structures. The individual and the total strain energy release rates are presented across the width and for various debond lengths. The results of analyses from the plate element-based technique are compared with the results of analyses based on 3D models.

\section{Analysis}

The skin-stiffener debond configuration is presented in this section. Definitions and procedures used in the literature for the calculation of the strain energy release rates are briefly discussed. Finally, the issues that will be quantified are presented and discussed.

\section{Skin-Stiffener Modeling}

The configuration and loading of the stitched skinstiffened panel shown in Figure 1(a) includes 
complicated configurational details such as stiffener flanges, stiffener webs and intercostals. Simplified configurations such as that shown in Figure 1(b) can be used in these analyses and are beneficial to quantify the effects of the critical assumptions and parameters of interest on the calculation of strain energy release rates. Figure 1(c) shows the details of the debonded region of the configuration including the stitch spacing and the skin and stiffener flange thicknesses.

The debonds are modeled with three-dimensional quadratic 20 node hexahedra and shear-deformable plate elements as shown in Figures 2(a) and 2(b), respectively. The 3D element and plate element analyses use four 20 node brick elements and one 9 node shear deformable plate element, respectively, through-the-thickness of both the flange and the skin. In-plane dimensions of both $3 \mathrm{D}$ and plate elements are $0.0625 \mathrm{in}$. by $0.0625 \mathrm{in}$. In both of the analyses, the stitches are modeled as nonlinear spring elements. Results from the three-dimensional analyses, which account for the details of through-the-thickness shear deformation, are used as a baseline for comparison with the plate element results. The plate element analyses were performed using STAGS 480 sheardeformable quadratic plate elements ${ }^{19-20}$ and the 3D element analyses were performed using ABAQUS C3D20 quadratic elements ${ }^{21}$.

In all of the plate finite element models considered herein, the skin and the stiffener are modeled as separate, flat plates. Conventional plate modeling inherently assumes that the reference surface of the plate coincides with the middle surface. Thus, the skin and stiffener are usually modeled by plate elements with nodes at their respective mid-planes. This conventional method is not convenient for modeling debonding because it entails complex constraints to tie the flange nodes to the corresponding skin nodes. A more convenient approach, taken in the present analysis, is to place the skin nodes and the stiffener nodes along the interface between the skin and the stiffener. The positioning of these nodes at the interface is performed by defining an offset distance from the mid-plane of both the skin and the stiffener (see references 17 and 18), as shown in Figure 3.

The configuration was modeled as an infinitely repeating strip of length $L_{l}=2.5 \mathrm{in}$. and $L_{2}=1.5 \mathrm{in}$. and a width corresponding to the $y$-direction stitch spacing of $s_{y}=0.125$ in. The skin and stiffener flange have equal thickness, $t$, of either $0.110 \mathrm{in}$. or $0.220 \mathrm{in}$. and are subjected to cylindrical bending repeating unit boundary conditions $\left(\mathrm{v}=0, \theta_{\mathrm{x}}=0\right.$ on $y= \pm s_{\mathrm{y}} / 2$ in Figure 1(b) at a model width corresponding to the stitch row spacing, $s_{y}$.
Material and skin thicknesses are representative of a hybrid IM7/3501-6 and AS4/3501-6 warp-knit fabric stitched composite upper wing skin. ${ }^{1}$ The material consists of IM7 yarns in the axial direction and AS4 yarns in the off-axis directions. Each stack of material is assumed to be oriented with its primary axis in the $x$-direction and having a thickness of 0.055 in. The overall density of the fabric expressed in areal weight is $0.577 \mathrm{oz} . / \mathrm{ft}^{2}, 1.21 \mathrm{oz} . / \mathrm{ft}{ }^{2}{ }^{2}$ and $0.651 \mathrm{oz} . / \mathrm{ft}^{2}{ }^{2}$ for the forty-five, zero and ninety degree plies, respectively. The equivalent laminate stacking sequence of each stack of material is $(45 /-45 / 0 / 90 / 0 /-45 / 45)_{n s}$ where $n=2$ for both the skin and stiffener.

In these analyses, the laminates are assumed to be homogeneous with axial properties determined experimentally and all others estimated using the equivalent stacking sequence and classical lamination theory as

$$
\begin{array}{lll}
\mathrm{E}_{11}=11.7 M s i & \mu_{12}=2.50 M s i & v_{12}=0.40 \\
\mathrm{E}_{22}=5.14 \mathrm{Msi} & \mu_{13}=1.77 \mathrm{Msi} & \mathrm{v}_{13}=0.30 \\
\mathrm{E}_{33}=1.79 \mathrm{Msi} & \mu_{23}=0.88 \mathrm{Msi} & \mathrm{v}_{23}=0.30
\end{array}
$$

where $E_{\mathrm{ii}}, \mu_{\mathrm{ij}}, v_{\mathrm{ij}}(\mathrm{i}, \mathrm{j}=1,2,3)$ are the Young's moduli, shear moduli, and Poisson's ratio, respectively, and the subscripts 1,2,3 represent the fiber, transverse and out-of-plane directions, respectively. The stitch spacings, $s_{\mathrm{x}}$ and $s_{\mathrm{y}}$, were 0.125 in. in the $x$ - and $y$ directions, respectively.

\section{Strain Energy Release Rates}

Figure 4 shows an edge crack of length $a$ in a large plate of unit thickness. The strain energy release rate, $G$, for self-similar crack growth under constant load is defined $\mathrm{as}^{22}$

$G=\frac{\partial W}{\partial A}-\frac{\partial U}{\partial A}$

where $U$ is the total strain energy of the body, $W$ is the external work done on the body and $A$ is the crack surface area.

\section{D Analysis}

To calculate strain energy release rates, $G$, Irwin proposed the virtual crack closure technique (VCCT) ${ }^{23}$. Here, $G$ is calculated by considering the work required to close the crack from $a+\Delta$ to $a$ (see Figure 4(a). Energy release rate can be separated into mode I and mode II components and calculated by 


$$
\begin{aligned}
& G_{I}=\lim _{\Delta \rightarrow 0}\left\{\frac{-1}{2 \Delta} \int_{0}^{\Delta} \sigma_{z}(x) w(\Delta-x) d x\right\} \\
& G_{I I}=\lim _{\Delta \rightarrow 0}\left\{\frac{-1}{2 \Delta} \int_{0}^{\Delta} \sigma_{x z}(x) u(\Delta-x) d x\right\} \\
& G_{\text {Total }}=G_{I}+G_{I I}
\end{aligned}
$$

where $w$ and $u$ are the crack opening and sliding displacements, respectively, and $\sigma_{\mathrm{z}}$ and $\sigma_{\mathrm{xz}}$ are the normal and shear stresses ahead of the crack tip. Several methods are available to calculate the strain energy release rates from a single finite element solution using nodal forces ahead of the crack and the crack opening displacements behind the crack. ${ }^{2425}$

\section{D Analysis}

The VCCT can also be applied to 3D configurations such as the one shown in Figure 4(b). Here, $G$ can be separated into mode I, mode II and mode III components by

$$
\begin{aligned}
& G_{I}=\lim _{\Delta \rightarrow 0}\left\{\frac{-1}{2 \Delta \delta y} \int_{y}^{y+\delta y}\left[\int_{0}^{\Delta} \sigma_{z}(x, y, 0) w(\Delta-x, y, 0) d x\right] d y\right\} \\
& G_{I I}=\lim _{\Delta \rightarrow 0}\left\{\frac{-1}{2 \Delta \delta y} \int_{y}^{y+\delta y}\left[\int_{0}^{\Delta} \sigma_{x z}(x, y, 0) u(\Delta-x, y, 0) d x\right] d y\right\} \\
& G_{I I I}=\lim _{\Delta \rightarrow 0}\left\{\frac{-1}{2 \Delta \delta y} \int_{y}^{y+\delta y}\left[\int_{0}^{\Delta} \sigma_{x y}(x, y, 0) v(\Delta-x, y, 0) d x\right] d y\right\} \\
& G_{\text {Total }}=G_{I}+G_{I I}+G_{I I I}
\end{aligned}
$$

where $u, v$ and $w$ are the crack face displacements, and $\sigma_{z}, \sigma_{x z}$ and $\sigma_{x y}$ are the corresponding normal and shear stresses ahead of the crack tip.

The VCCT has been implemented in threedimensional finite element analyses, where the region near the crack tip is modeled by either brick elements or plate elements. As in two-dimensional analysis, the individual mode strain energy release rates can be calculated from the nodal forces and displacements near the crack tip obtained from a single finite element analysis.

A representation of the 9-noded plate elements near a debond front with rectangular grid type modeling is shown in Figure 5 with element lengths of 0.0625 in. in both the $x$ - and $y$-directions. Reference 26 suggests that allowing the elements ahead of the debond front to have free rotations ensures accurate modeling and evaluation of the strain energy release rates. If there are free rotations ahead of the debond front, then the $G$ values can be calculated using the nodal forces $\left(F_{x}, F_{y}\right.$, $\left.F_{z}\right)$ and displacements $(u, v, w)$ near the debond front and the increment of new debond area created as (see Figure 5) ${ }^{18}$

Mode-I components:

$$
\begin{aligned}
& \left(G_{I}\right) i=-\frac{1}{2 \Delta b_{i}}\left[F_{z_{l}}\left(w_{p}-w_{p^{\prime}}\right)+F_{z_{e}}\left(w_{l}-w_{l^{\prime}}\right)\right] \\
& \left(G_{I}\right) j=-\frac{1}{2 \Delta b_{j}}\left[F_{z_{j}}\left(w_{q}-w_{q^{\prime}}\right)+F_{z_{j}}\left(w_{m}-w_{m^{\prime}}\right)\right] \\
& \left(G_{I}\right) k=-\frac{1}{2 \Delta b_{k}}\left[F_{z_{k}}\left(w_{r}-w_{r^{\prime}}\right)+F_{z_{3}}\left(w_{n}-w_{n^{\prime}}\right)\right]
\end{aligned}
$$

Mode-II components:

$$
\begin{aligned}
& \left(G_{I I}\right) i=-\frac{1}{2 \Delta b_{i}}\left[F_{x_{i}}\left(u_{p}-u_{p^{\prime}}\right)+F_{x_{c}}\left(u_{l}-u_{l^{\prime}}\right)\right] \\
& \left(G_{I I}\right) j=-\frac{1}{2 \Delta b_{j}}\left[F_{x_{j}}\left(u_{q}-u_{q^{\prime}}\right)+F_{x_{j}}\left(u_{m}-u_{m^{\prime}}\right)\right] \\
& \left(G_{I I}\right) k=-\frac{1}{2 \Delta b_{k}}\left[F_{x_{k}}\left(u_{r}-u_{r^{\prime}}\right)+F_{x_{s}}\left(u_{n}-u_{n^{\prime}}\right)\right]
\end{aligned}
$$

Mode-III components:

$$
\begin{aligned}
& \left(G_{I I I}\right)_{i}=-\frac{1}{2 \Delta b_{i}}\left[F_{y_{i}}\left(v_{p}-v_{p^{\prime}}\right)+F_{y_{e}}\left(v_{l}-v_{l^{\prime}}\right)\right] \\
& \left(G_{I I}\right) j=-\frac{1}{2 \Delta b_{j}}\left[F_{y_{j}}\left(v_{q}-v_{q^{\prime}}\right)+F_{y_{j}}\left(v_{m}-v_{m^{\prime}}\right)\right] \\
& \left(G_{I I I}\right) k=-\frac{1}{2 \Delta b_{k}}\left[F_{y_{k}}\left(v_{r}-v_{r^{\prime}}\right)+F_{y_{s}}\left(v_{n}-v_{n^{\prime}}\right)\right]
\end{aligned}
$$

with

$\left(G_{\text {Total }}\right)_{\gamma}=\left.\left(G_{I}+G_{I I}+G_{I I I}\right)\right|_{\gamma}$, and

$\gamma=\mathrm{i}, \mathrm{j}$ and $\mathrm{k}$ indicate nodes at the debond front as shown in Figure 5(b).

The elements are assumed to have the same length, $\Delta$, ahead of and behind the debond front (as shown in Figure 5). In Eqs. 4-6, the equivalent widths apportioned to the two corner debond-front nodes are $b_{i}$ and $b_{k}$, and to the midside debond front node is $b_{j}$. These are

$$
\begin{aligned}
b_{i} & =\frac{1}{6}\left[b_{J-1}+b_{J}\right], \\
b_{j} & =\frac{2}{3} b_{J}, \\
b_{k} & =\frac{1}{6}\left[b_{J}+b_{J+1}\right],
\end{aligned}
$$

where $b_{J-1}, b_{J}$ and $b_{J+I}$ are the widths of element rows $J-1, J$ and $J+1$, respectively, as shown in Figure 5(b).

Note that this modeling strategy, which assumes no rotational constraints ahead of the debond front, is termed "Technique- $B$ " in references 17-18. The strain energy release rates along the debond front of the mixed-mode skin-stiffener debond configurations are calculated using equations (4)-(8). 
Modeling Stitches

Unlike the two-dimensional plane strain and threedimensional solid models considered in references 512 , the plate element-based modeling technique does not allow through-the-thickness modeling of details such as the stitches; nor does it allow nodal connections other than at the plate element reference surface. Thus, in the present technique, the stitches are not modeled as spar or beam elements, but rather as nonlinear spring elements implemented as "fastener elements" within the plate element analysis. ${ }^{19-20}$

Since the three-dimensional models have nodes through-the-thickness, spar or beam elements can be used to model the stitches as in references 5-12. In such an implementation, nonlinearity of the stitches can be simulated by either changing the location of $z$ direction nodal connectivity (explicitly simulating a debonded stitch) or by using a nonlinear constitutive relationship within the spar/beam elements. However, the primary objective of this paper is to compare the results of the plate element models with similar 3D element models. Hence, the modeling strategy used in the 3D element-based models implements nonlinear spring elements with the same nonlinear compliance as is used in the plate elementbased models.

The nonlinear spring elements have both axial and shear stiffnesses, $K_{\text {axial }}$ and $K_{\text {shear }}$ and are schematically shown as springs in Figure 1(c). Only the spring elements behind the debond front $\left(L_{l}-a<x<L_{l}\right.$ in Figure 1(b) carry load since the nodes bounding the interface of the elements ahead of the debond front are coupled using constraint equations to have identical translational displacements. Stitches are considered in the model only along the debonded length of the skin and stiffener, so the number of spring elements in the model representing the stitches in the structure is dependent on the debond length. The stitch elements are evenly spaced along the line $y=z=0$ over the debonded length of the model $\left(L_{1}-a<x<L_{1}\right)$ in regular intervals of 0.125 in. corresponding to the stitch locations. The modeling is performed such that a finite element node exists at these locations.

Compliance curves for both axial and shear behavior of the stitches were developed in reference 27 using flatwise tension and double lap shear tests (see Figure 6), respectively. These compliance curves represent the net behavior of the stitch due to stitch material nonlinearity and stitch debonding. ${ }^{27}$

A piecewise linear representation of the compliance data is used in the finite element analyses. The points used in the linearization of the compliance curves are shown as solid circles in Figure 6. Examination of the flatwise tension test data revealed that the axial compliance of the stitches increases from approximately (1/77000) in./lb. initially to (1/2050) in./lb. near failure. Similar examination of the double lap shear test data showed that the shear compliance of the stitches increases from approximately (1/18200) in./lb. initially to $(1 / 1600)$ in./lb. near failure.

Since the axial and shear responses of the stitches shown in Figure 6 were determined independently using flatwise tension and double lap shear tests, their responses must be considered to be independent in the analysis as well. Also note that failure of the stitches occurs at a load of $58 \mathrm{lb}$. per stitch in tension and 38 lb. per stitch in shear. These stiffnesses and failure loads will be used for the plate and volume elementbased characterizations in this paper.

\section{Modeling the Contact Problem}

Closure of the debond faces may occur once the debond in the stitched configurations is of sufficient length. In the finite element analysis, contact of the faces is allowed, while interpenetration of the faces is not. Interpenetration of the faces can be prevented either by adding contact elements (STAGS 810 PAD or ABAQUS GAP elements) to the model between the debond faces where interpenetration is likely to occur or by adding multipoint constraints along a known region of interpenetration to impose the requirement of identical $z$-direction $(w)$ displacements among elements in contact. No constraint on the relative sliding displacements $(u, v)$ is imposed using either technique. The multipoint constraint-based procedure was used in the present analysis even though it requires that multiple analyses be executed to determine the actual contact length. This choice was made because of issues concerning the tolerances on overclosure allowed with the contact elements.

\section{Skin-Stiffener Configuration Results}

Three-dimensional analyses that model the crosssectional deformation of the skin and stiffener are inherently more accurate than plate element-based analyses that make the assumption that plane sections remain plane throughout the thickness. However, the plate assumptions become increasingly valid as the slenderness ratio (ratio of plate length, $l$, to thickness, $2 t$ ) increases. Two skin and stiffener flange thicknesses are considered in the results that follow. The first has a thickness $(2 t)$ of $0.44 \mathrm{in}$. and an overall slenderness ratio $(l / 2 t)$ of 9.09 while the second has a thickness $(2 t)$ of 0.22 and an overall slenderness ratio $(l / 2 t)$ of 18.2 .

The magnitude of the applied loads was chosen to maintain the approximation of geometric linearity while loading the stitches beyond the first linearized segment of the curves shown in Figure 6. Bending 
loads, $q$, of $100.0 \mathrm{lb}$./in. and $50.0 \mathrm{lb}$./in. were applied to the $l / 2 t=9.09$ and $l / 2 t=18.2$ configurations, respectively. Values of strain energy release rates shown in Figures 7,9 and 10 have been normalized by $q^{2}$, while values of stitch force and section rotation shown in Figures 8 and 11 are not normalized.

\section{Strain Energy Release Rates}

Figure 7 shows a comparison between the strain energy release rates obtained from plate element and 3D element techniques for unstitched and stitched versions of the configuration shown in Figure 1. In Figure $7, G^{U}$ and $G^{S}$ denote strain energy release rates corresponding to unstitched and stitched configurations, respectively. Both the plate and 3D analyses show that the stitches are effective in reducing the values of $G_{\mathrm{I}}$ and $G_{\mathrm{II}}$ as the debond length increases. The mode-I strain energy release rate, $G_{\mathrm{I}}$, decreases to near-zero values as the stitches begin to carry load while $G_{\text {II }}$ reduces to small but nonzero values for long debonds.

Figure 7 (a) shows the results from a configuration with a slenderness ratio of $l / 2 t=9.09$ The plate element-based technique predicts values of $G_{1}$ and $G_{\text {II }}$ for the unstitched configuration that are consistently less than the values from the $3 \mathrm{D}$ values. The values of $G_{\mathrm{II}}$ for the stitched configuration modeled with plate elements are also less than those obtained from the 3D analyses. In contrast, the values of $G_{\mathrm{I}}$ for the stitched configuration modeled with plate elements are somewhat larger than for the $3 \mathrm{D}$ analyses. However, both analyses predict $G_{\mathrm{I}}$ reaching a value near zero at approximately the same debond length.

Figure 7 (b) shows a similar comparison between plate and 3D analysis values, but for a slenderness ratio of $l / 2 t=18.2$. For both the unstitched and stitched configurations, the plate element-based technique predicts values of $G_{\mathrm{I}}$ and $G_{\mathrm{II}}$ that are very close to those obtained from the $3 \mathrm{D}$ analyses. A comparison of the results obtained for these two configurations indicates that the validity of the plate element-based analyses improves with increasing slenderness ratio.

\section{Stitch Forces}

Figure 8 shows axial and shear stitch forces for the load bearing stitches at both slenderness ratios. Figures 8(a) and 8(b) show the normalized axial and shear force in the stitches for $l / 2 t=9.09$ and 18.2, respectively. The stitch forces were evaluated from the finite element model with increments of debond growth of 0.125 in., so the force corresponding to the first 0.125 in. of debond growth beyond a given stitch location in the finite element model was not recovered in the analysis and is represented by the thin lines in the figure. As seen in Figure 8(a), only stitches 1 through 3 have nonzero axial force $\left(F_{\text {axial }}\right)$ in the $l / 2 t=9.09$ configuration. The axial force reaches a near-constant value for debond lengths corresponding to the region of zero mode-I $(a / t>2.7)$. In the case of $l / 2 t=18.2$, only stitches 1 and 2 carry axial load. The axial force reaches a near-constant value for debonds of length $a / t>5.4$. Although the overall axial behavior of the nonlinear spring elements in both the plate element and 3D analyses are similar, the nonlinear spring elements implemented in the plate element analyses consistently carry more axial load than those in the $3 \mathrm{D}$ analyses.

Shearing forces $\left(F_{\text {shear }}\right)$, shown in Figures 8(c) and $8(\mathrm{~d})$, are also present in the stitches and are nonzero for all of the stitches along the debond. The shearing forces in the stitches in the $l / 2 t=18.2$ configuration are slightly larger than the shearing forces in the $l / 2 t=9.09$ configuration over the range of debond lengths considered.

The shearing forces in the nonlinear spring elements in the plate element analyses agree very well with those from the $3 \mathrm{D}$ analyses.

\section{Strain Energy Release Rate Distribution}

Figure 9 shows the strain energy release rate distribution as a function of position across the width of the stitched configurations with debonds of length, $a / t=1.14$ and 2.27 for configurations with $l / 2 t=9.09$ and 18.2, respectively. For both configurations, the plate element analysis predicts $G_{1}$-values close to the $3 \mathrm{D}$ values except at $y$-locations near the stitch locations $(y / b=0)$. $\quad G_{\text {II }}$ values determined with the plate element-based technique tend to be less than those determined with the 3D analyses.

Figures 7 and 9 suggest that the plate element-based models can predict the overall effect of the stitches on the debond but are not as effective in predicting local $y$-direction gradients of strain energy release rate. However, in an analysis of axially loaded stitched lap joints, similar plate element-based models captured the local effects of stitching for finite and infinite width configurations. ${ }^{28}$

The boundary conditions in the skin-stiffener models were relaxed by removing the cylindrical bending conditions from one edge of the model. A free edge effect near $y / b=0.5$ results. The $G$-values determined for this new configuration are shown in Figure 10. The figure shows $G_{\mathrm{I}}$ and $G_{\mathrm{II}}$ distributions across the width of a configuration of width, $b$, where $y / b=0$ corresponds to the stitch locations and $y / b=0.5$ corresponds to the free edge. The plate element-based analyses capture much of the effect of the free edge on the $G$-values and correlate well with those from the $3 \mathrm{D}$ analyses except near the stitch locations. The 
loads, $q$, of $100.0 \mathrm{lb}$./in. and $50.0 \mathrm{lb}$./in. were applied to the $l / 2 t=9.09$ and $l / 2 t=18.2$ configurations, respectively. Values of strain energy release rates shown in Figures 7,9 and 10 have been normalized by $q^{2}$, while values of stitch force and section rotation shown in Figures 8 and 11 are not normalized.

\section{Strain Energy Release Rates}

Figure 7 shows a comparison between the strain energy release rates obtained from plate element and 3D element techniques for unstitched and stitched versions of the configuration shown in Figure 1. In Figure $7, G^{U}$ and $G^{S}$ denote strain energy release rates corresponding to unstitched and stitched configurations, respectively. Both the plate and 3D analyses show that the stitches are effective in reducing the values of $G_{\mathrm{I}}$ and $G_{\mathrm{II}}$ as the debond length increases. The mode-I strain energy release rate, $G_{\mathrm{I}}$, decreases to near-zero values as the stitches begin to carry load while $G_{\text {II }}$ reduces to small but nonzero values for long debonds.

Figure 7 (a) shows the results from a configuration with a slenderness ratio of $l / 2 t=9.09$ The plate element-based technique predicts values of $G_{1}$ and $G_{\text {II }}$ for the unstitched configuration that are consistently less than the values from the $3 \mathrm{D}$ values. The values of $G_{\mathrm{II}}$ for the stitched configuration modeled with plate elements are also less than those obtained from the 3D analyses. In contrast, the values of $G_{\mathrm{I}}$ for the stitched configuration modeled with plate elements are somewhat larger than for the $3 \mathrm{D}$ analyses. However, both analyses predict $G_{\mathrm{I}}$ reaching a value near zero at approximately the same debond length.

Figure 7 (b) shows a similar comparison between plate and 3D analysis values, but for a slenderness ratio of $l / 2 t=18.2$. For both the unstitched and stitched configurations, the plate element-based technique predicts values of $G_{\mathrm{I}}$ and $G_{\mathrm{II}}$ that are very close to those obtained from the $3 \mathrm{D}$ analyses. A comparison of the results obtained for these two configurations indicates that the validity of the plate element-based analyses improves with increasing slenderness ratio.

\section{Stitch Forces}

Figure 8 shows axial and shear stitch forces for the load bearing stitches at both slenderness ratios. Figures 8(a) and 8(b) show the normalized axial and shear force in the stitches for $l / 2 t=9.09$ and 18.2, respectively. The stitch forces were evaluated from the finite element model with increments of debond growth of 0.125 in., so the force corresponding to the first 0.125 in. of debond growth beyond a given stitch location in the finite element model was not recovered in the analysis and is represented by the thin lines in the figure. As seen in Figure 8(a), only stitches 1 through 3 have nonzero axial force $\left(F_{\text {axial }}\right)$ in the $l / 2 t=9.09$ configuration. The axial force reaches a near-constant value for debond lengths corresponding to the region of zero mode-I $(a / t>2.7)$. In the case of $l / 2 t=18.2$, only stitches 1 and 2 carry axial load. The axial force reaches a near-constant value for debonds of length $a / t>5.4$. Although the overall axial behavior of the nonlinear spring elements in both the plate element and 3D analyses are similar, the nonlinear spring elements implemented in the plate element analyses consistently carry more axial load than those in the $3 \mathrm{D}$ analyses.

Shearing forces $\left(F_{\text {shear }}\right)$, shown in Figures 8(c) and $8(\mathrm{~d})$, are also present in the stitches and are nonzero for all of the stitches along the debond. The shearing forces in the stitches in the $l / 2 t=18.2$ configuration are slightly larger than the shearing forces in the $l / 2 t=9.09$ configuration over the range of debond lengths considered.

The shearing forces in the nonlinear spring elements in the plate element analyses agree very well with those from the $3 \mathrm{D}$ analyses.

\section{Strain Energy Release Rate Distribution}

Figure 9 shows the strain energy release rate distribution as a function of position across the width of the stitched configurations with debonds of length, $a / t=1.14$ and 2.27 for configurations with $l / 2 t=9.09$ and 18.2, respectively. For both configurations, the plate element analysis predicts $G_{1}$-values close to the $3 \mathrm{D}$ values except at $y$-locations near the stitch locations $(y / b=0)$. $\quad G_{\text {II }}$ values determined with the plate element-based technique tend to be less than those determined with the 3D analyses.

Figures 7 and 9 suggest that the plate element-based models can predict the overall effect of the stitches on the debond but are not as effective in predicting local $y$-direction gradients of strain energy release rate. However, in an analysis of axially loaded stitched lap joints, similar plate element-based models captured the local effects of stitching for finite and infinite width configurations. ${ }^{28}$

The boundary conditions in the skin-stiffener models were relaxed by removing the cylindrical bending conditions from one edge of the model. A free edge effect near $y / b=0.5$ results. The $G$-values determined for this new configuration are shown in Figure 10. The figure shows $G_{\mathrm{I}}$ and $G_{\mathrm{II}}$ distributions across the width of a configuration of width, $b$, where $y / b=0$ corresponds to the stitch locations and $y / b=0.5$ corresponds to the free edge. The plate element-based analyses capture much of the effect of the free edge on the $G$-values and correlate well with those from the $3 \mathrm{D}$ analyses except near the stitch locations. The 
8. Sankar, B.V. and Sonik, V., "Modeling EndNotched Flexure Tests of Stitched Laminates," Proceedings of the American Society for Composites, ASC, 1995, pp. 172-181.

9. Byun, J.-H., Gillespie, Jr., J.W. and Chou, T.-W., "Mode I Delamination of a Three-Dimensional Fabric Composite," Journal of Composite Materials, Vol. 24, May 1990, pp. 497-518.

10. Flanagan, G. and Furrow, K., "Parametric Studies of Stitching Effectiveness for Preventing Substructure Disbond," Mechanics of Textile Composites Conference, NASA CP 3311, October 1995, pp. 539554.

11. Tsai, G.C., "Global/Local Stress Analysis of Stitched Composite Laminates," Proceedings of the 23rd International SAMPE Technical Conference, SAMPE, 1991, pp. 297-305.

12. Lee, C. and Liu, D., "Tensile Strength of Stitching Joint in Woven Glass Fabrics," Journal of Engineering Materials and Technology, Vol. 112, April 1990, pp. 125-130.

13. Glaessgen, E.H., Raju, I.S. and Poe, Jr., C.C., "Plate Element-Based Models for Mixed-Mode Debonding of Stitched Stiffened Panels," Fatigue and Fracture Mechanics: 30th Volume, STP 1360, ASTM, 1998, in press.

14. Glaessgen, E.H., Raju, I.S. and Poe, Jr., C.C., "Fracture Mechanics Analysis of Stitched StiffenerSkin Debonding," 39th AIAA/ASME/ASCE/AHS/ ASC Structures, Structural Dynamics, and Materials Conference, AIAA-98-2022-CP, AIAA, Washington, DC, 1998.

15. Wang, J.T., Raju, I.S., and Sleight, D.W., "Composite Skin Stiffener Debond Analyses Using Fracture Mechanics Approach with Shell Elements," Composites Engineering, Vol. 5, No. 2, 1995, pp. 277-296.

16. Raju, I.S., Sistla, R. and Krishnamurthy, T., "Fracture Mechanics Analyses for Skin-Stiffener Debonding," Engineering Fracture Mechanics, Vol. 54, No. 3, 1996, pp. 371-385.

17. Wang, J.T., Raju, I.S., Davila, C.G. and Sleight, D.W., "Computation of Strain Energy Release Rates for Skin-Stiffener Debonds Modeled with Plate Elements," 34th AIAA/ASME/ASCE/AHS Structures, Structural Dynamics and Materials Conference, AIAA Paper 93-1501-CP, 1993, pp. 1680-1692.
18. Wang, J.T. and Raju, I.S., "Strain Energy Release Rate Formulae for Skin-Stiffener Debond Modeled with Plate Elements," Engineering Fracture Mechanics, Vol. 54, No. 2, 1996, pp. 211-228.

19. Brogan, F.A., Rankin, C.C., Cabiness, H.D. and Loden, W.A., STAGS User Manual, Lockheed Martin Missiles and Space Co., July 1996.

20. Young, R.D., Rankin, C.C., Starnes, J. and Britt, V., Introduction to STAGS, Lecture Notes from a Workshop at NASA Langley Research Center, Hampton, VA, March 8-9, 1995.

21. ABAQUS User's Manual, v. 5.5, HKS, Inc., Pawtucket, R.I., 1995.

22. Broek, D., Elementary Engineering Fracture Mechanics, 4th Edition, Martinus Nijhoff, Boston, MA, 1987.

23. Irwin, G.R., "Fracture," In Handbuch der Physik, Vol. 6, 1958, pp. 551.

24. Rybicki, E.F. and Kanninen, M.F., "A Finite Element Calculation of Stress Intensity Factors by a Modified Crack Closure Integral," Engineering Fracture Mechanics, Vol. 9, 1977, pp. 931-938.

25. Raju, I.S., "Calculation of Strain-Energy Release Rates with Higher Order and Singular Finite Elements," Engineering Fracture Mechanics, Vol. 28, No. 3, 1987, pp. 251-274.

26. Glaessgen, E.H., Riddell, W.T. and Raju, I.S., "Effect of Shear Deformation and Continuity on Delamination Modeling with Plate Elements," 39th AIAA/ASME/ASCE/AHS/ASC Structures, Structural Dynamics, and Materials Conference, AIAA-98-2023CP, AIAA, Washington, DC, 1998.

27. Adams, D.O., "Stitch Compliance in Delaminated Composites," 29th SAMPE Technical Conference, Orlando, FL, October 28-31, 1997.

28. Glaessgen, E.H., Raju, I.S. and Poe, Jr., C.C., "Modeling the Influence of Stitching on Delamination Growth in Stitched Warp-Knit Composite Lap Joints," Proceedings of the 12th International Conference on Composite Materials, ICCM-99-449, 1999.

29. Adams, D.O., Private communication, March 1999. 


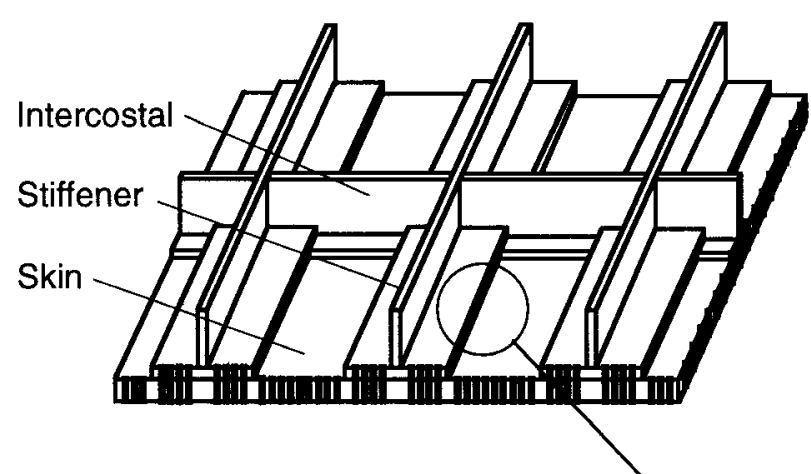

(a) Stitched composite panel

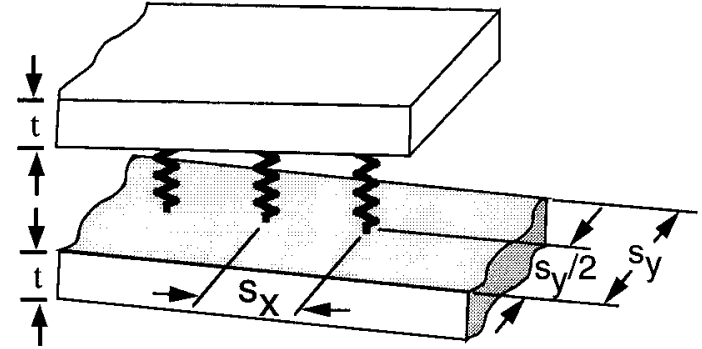

(c) Detail showing stitches modeled with nonlinear spring elements

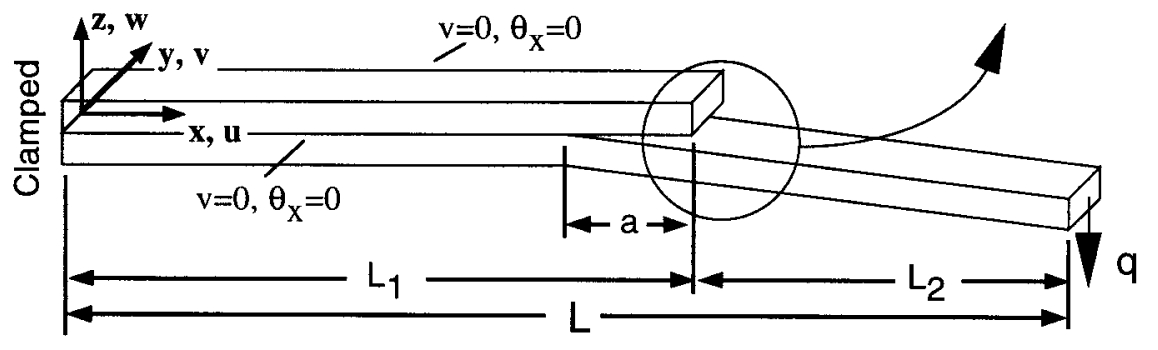

(b) Debond configuration

Figure 1. Stitched composite panel and debond configuration. 


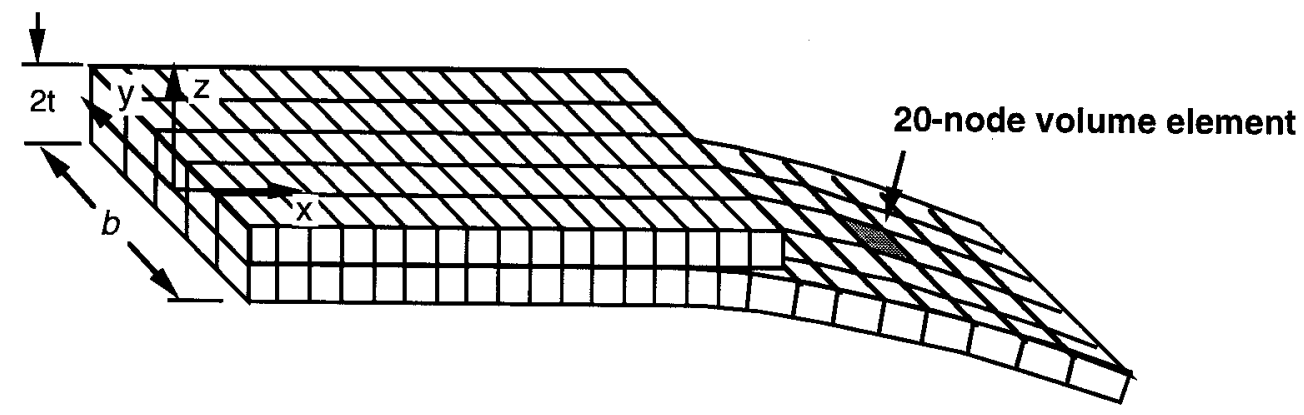

(a) Volume element model - cylindrical bending

8 elements through-the-thickness of skin and flange (2t)

Element size near debond front: $x=0.0625$ in., $y=0.0625$ in

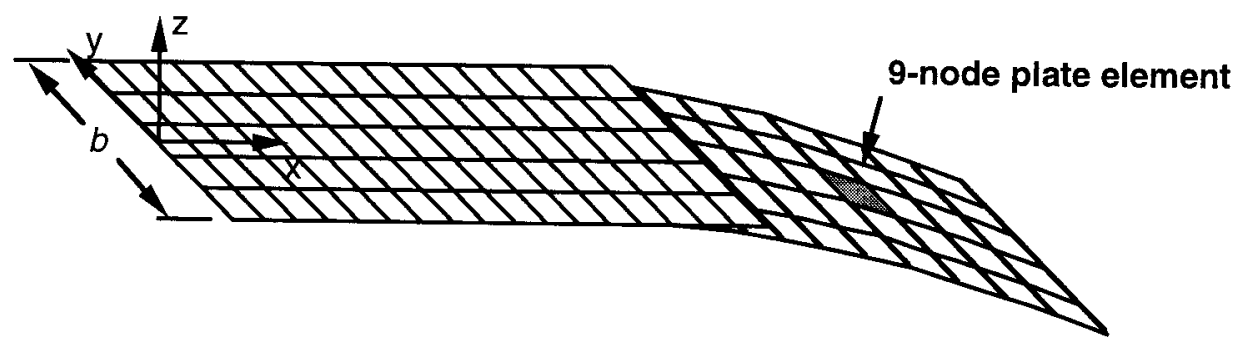

(b) Plate element model - cylindrical bending

2 elements through-the-thickness of skin and flange (2t)

Element size near debond front: $x=0.0625$ in., $y=0.0625$ in.

Figure 2. Flange-skin debond configuration and models. 


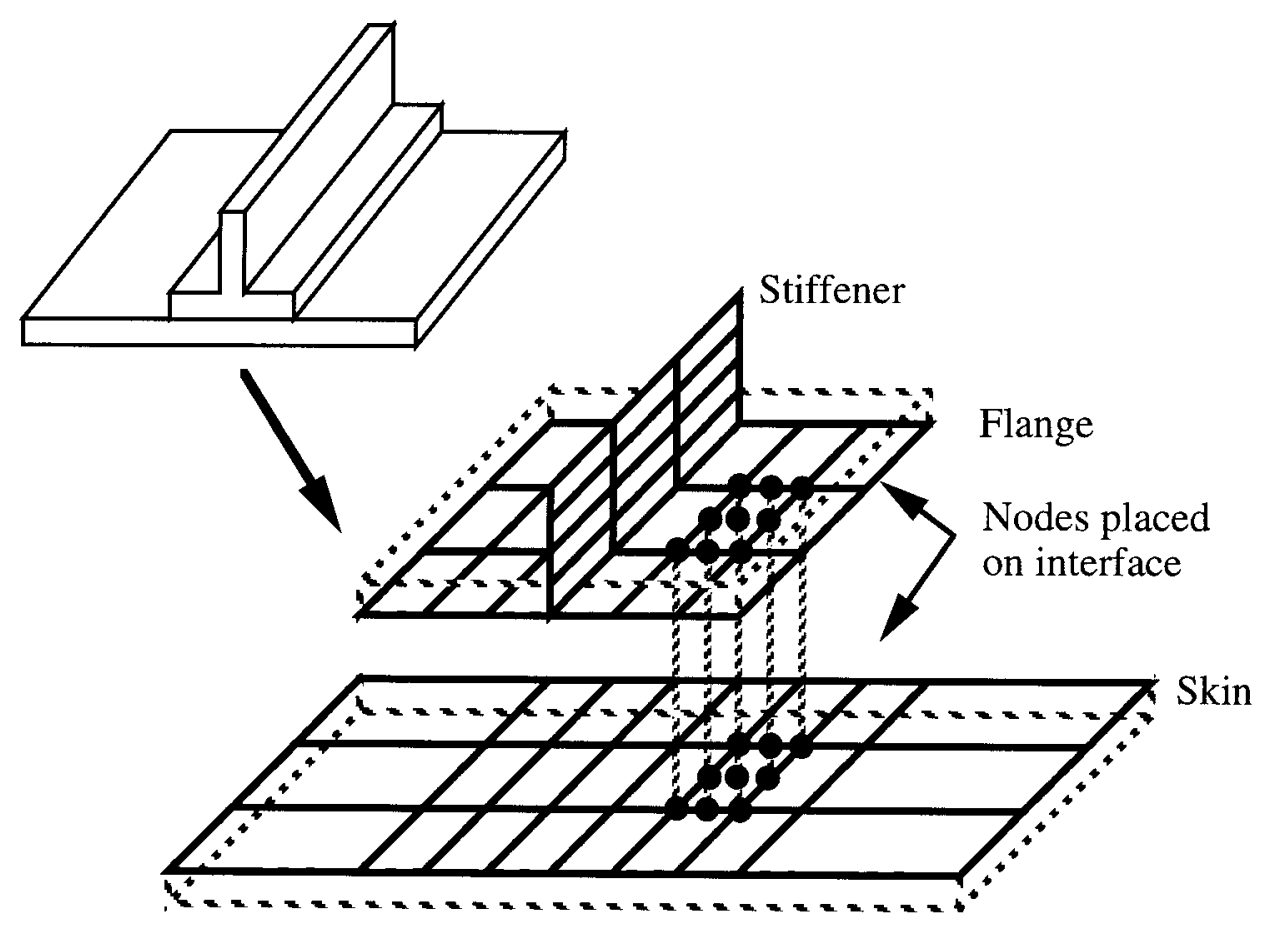

Figure 3. Plate element model of skin and stiffener.
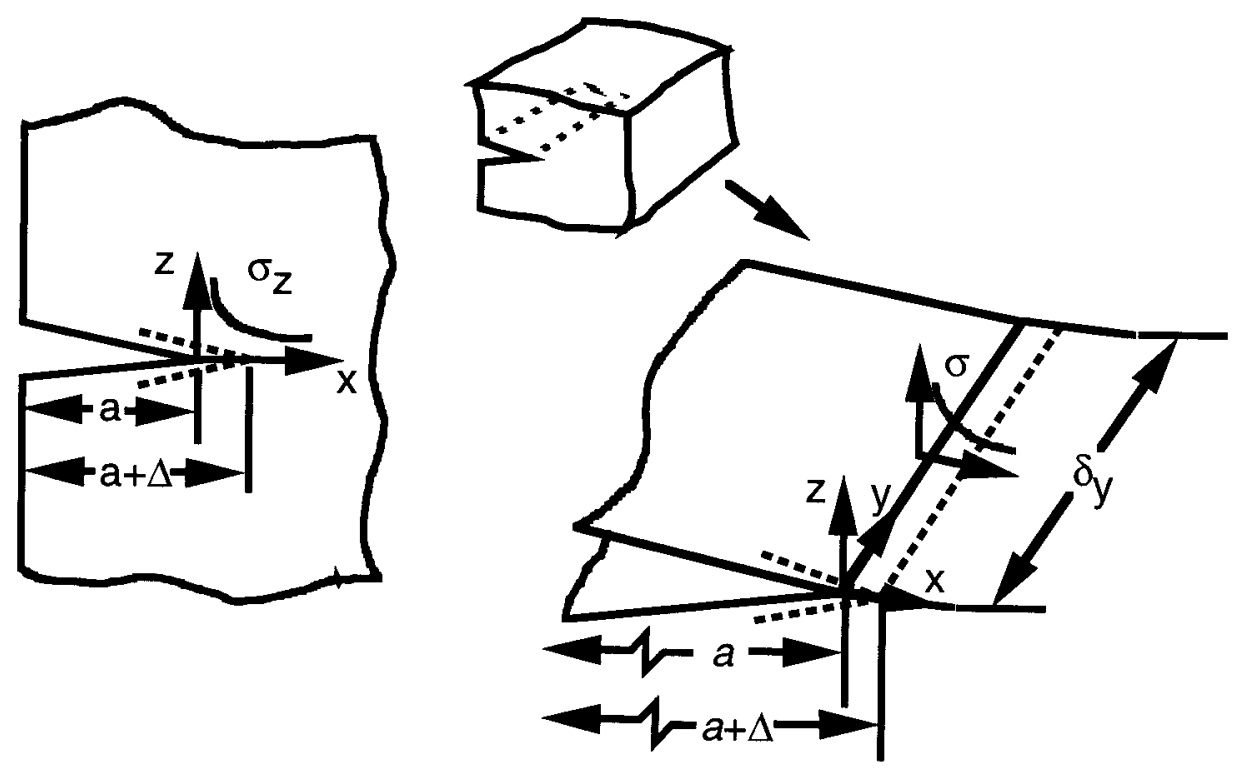

(a) Crack in 2D plate

(b) Through-crack in 3D body

Figure 4. VCCT approach for G-calculation. 


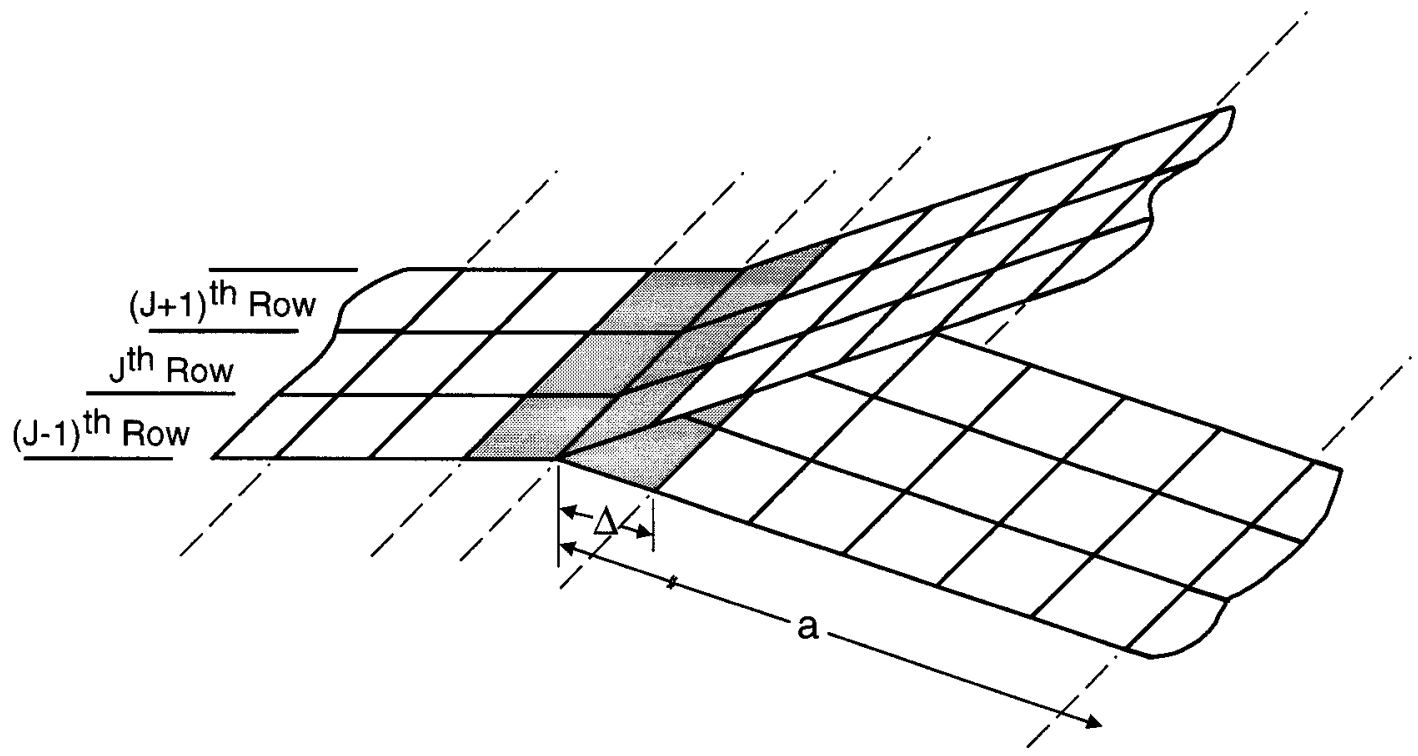

(a) Plate element modeling near the debond front

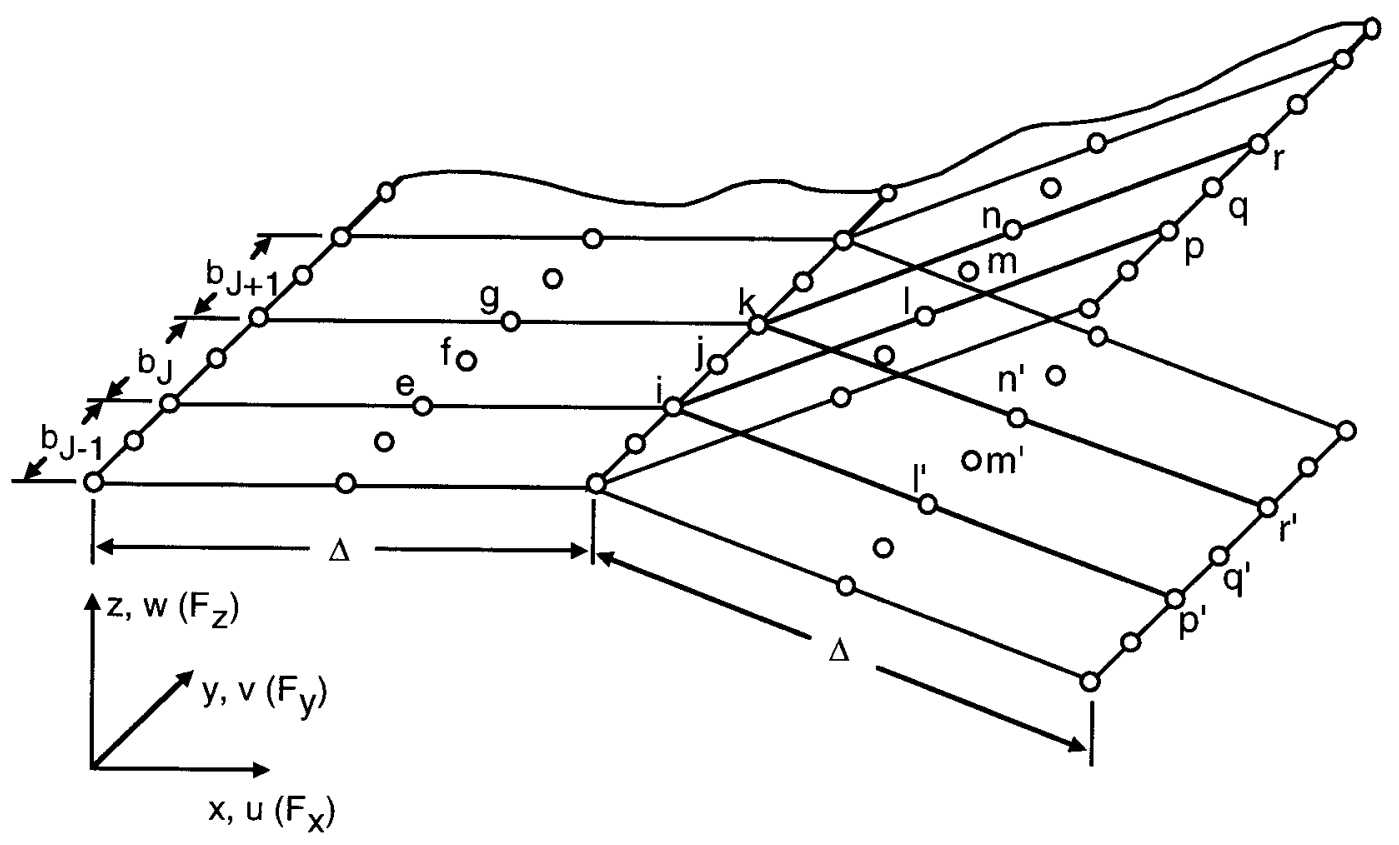

(b) Details of the model near the debond front

Figure 5. Debond configuration modeled using 9-node plate elements. 


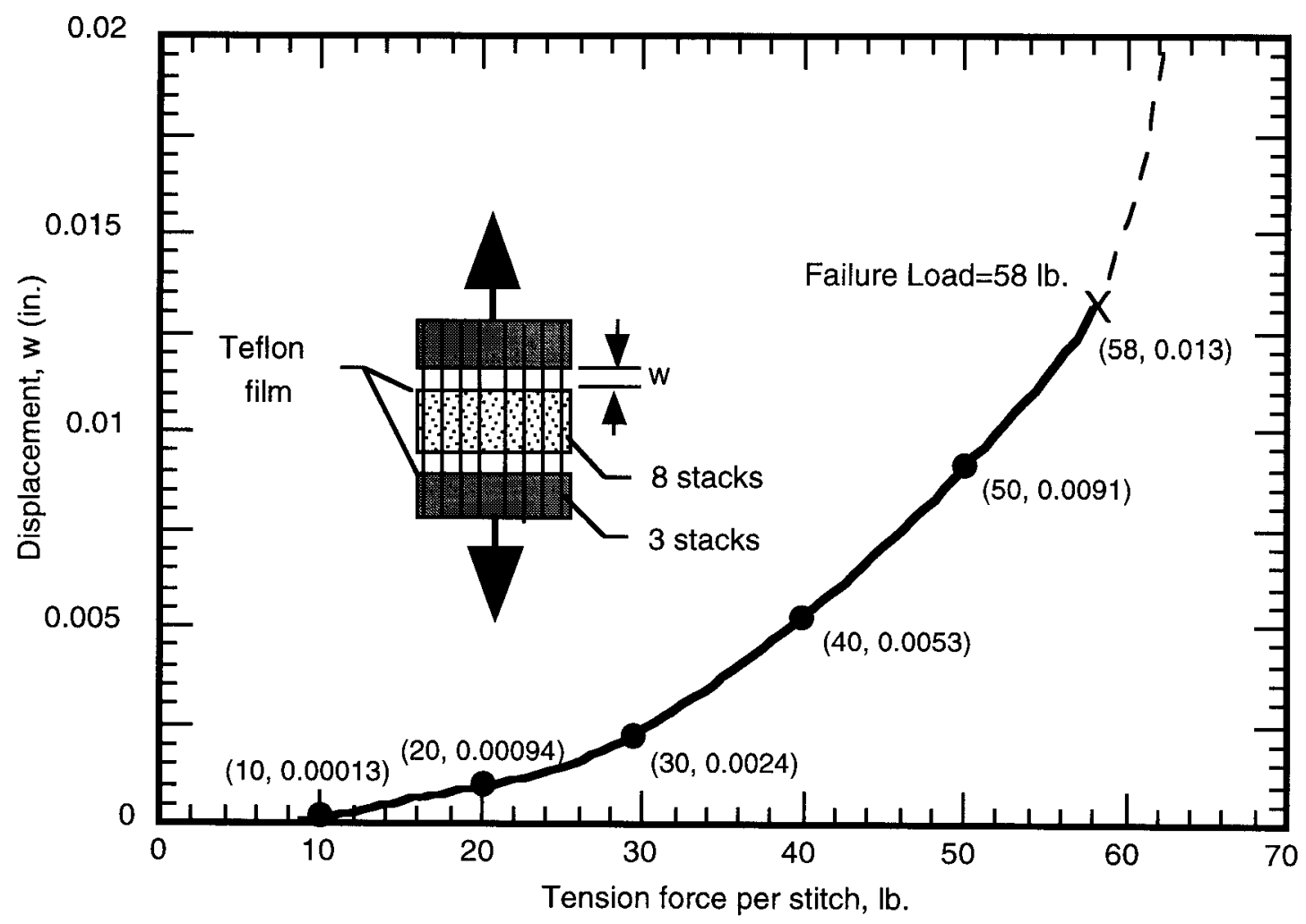

(a) Compliance of stitches in tension

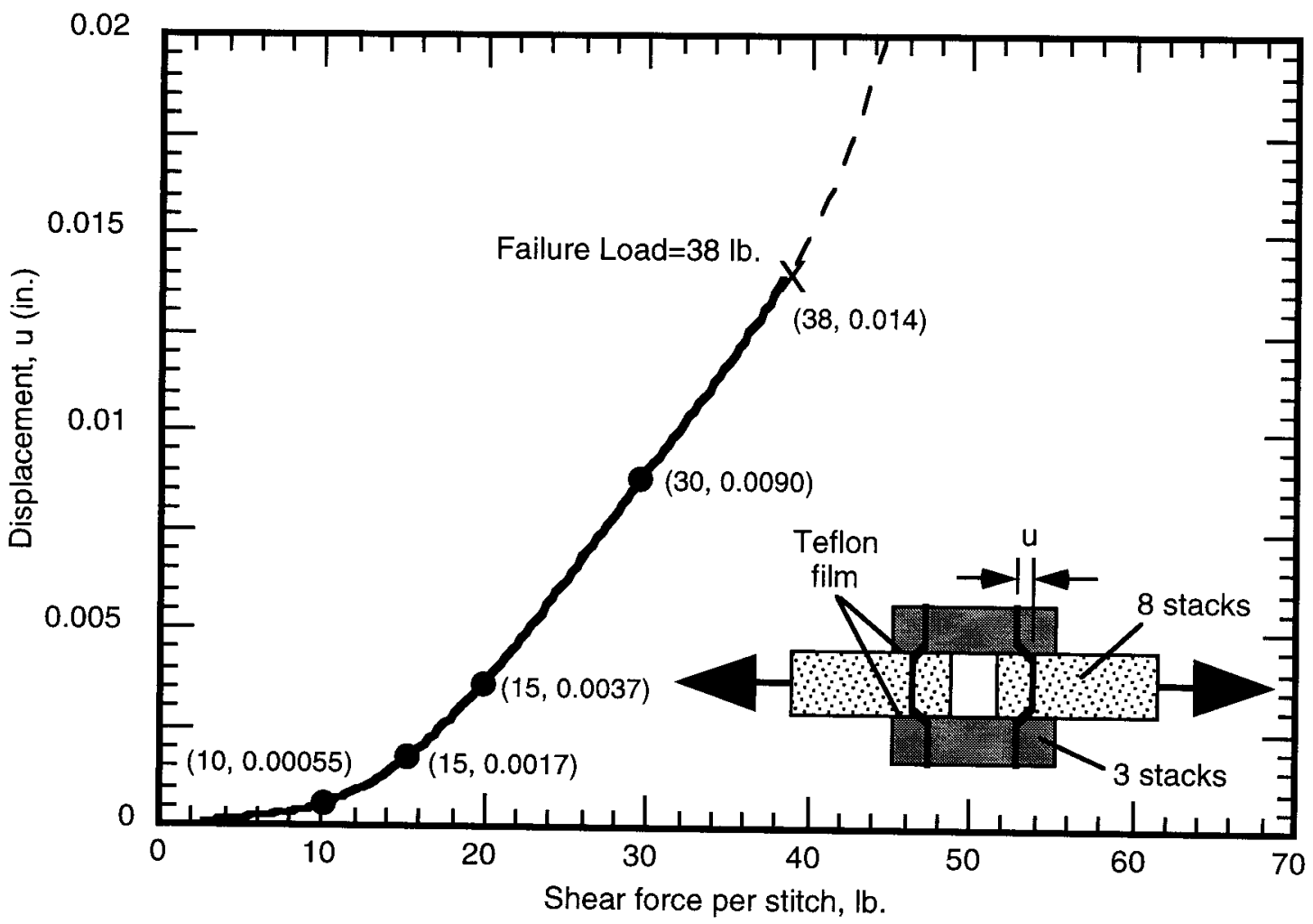

(b) Compliance of stitches in shear

Figure 6. Stitch compliance (experimental results taken from reference 27). 


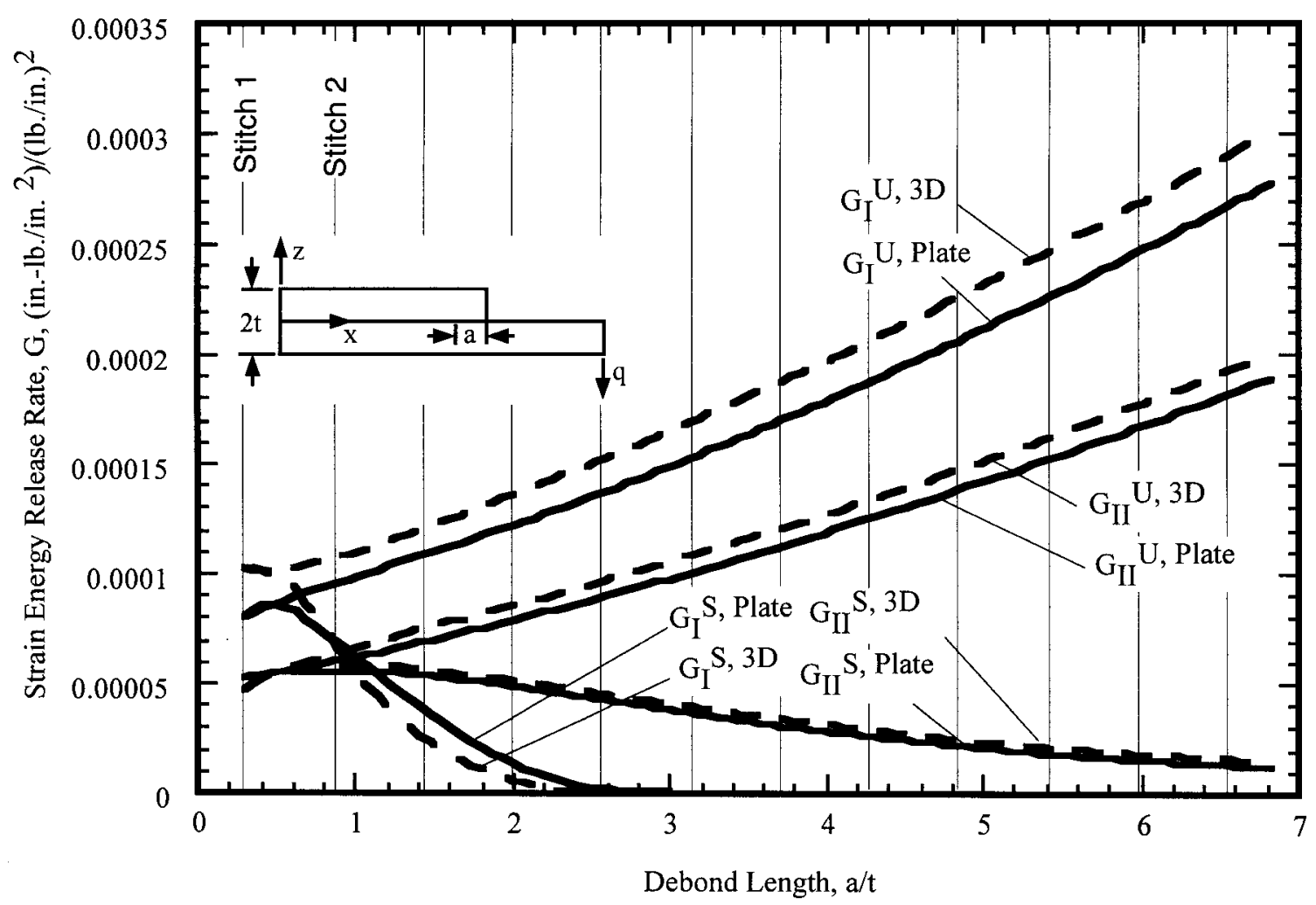

(a) Debond configurations with thickness, $1 / 2 t=9.09$

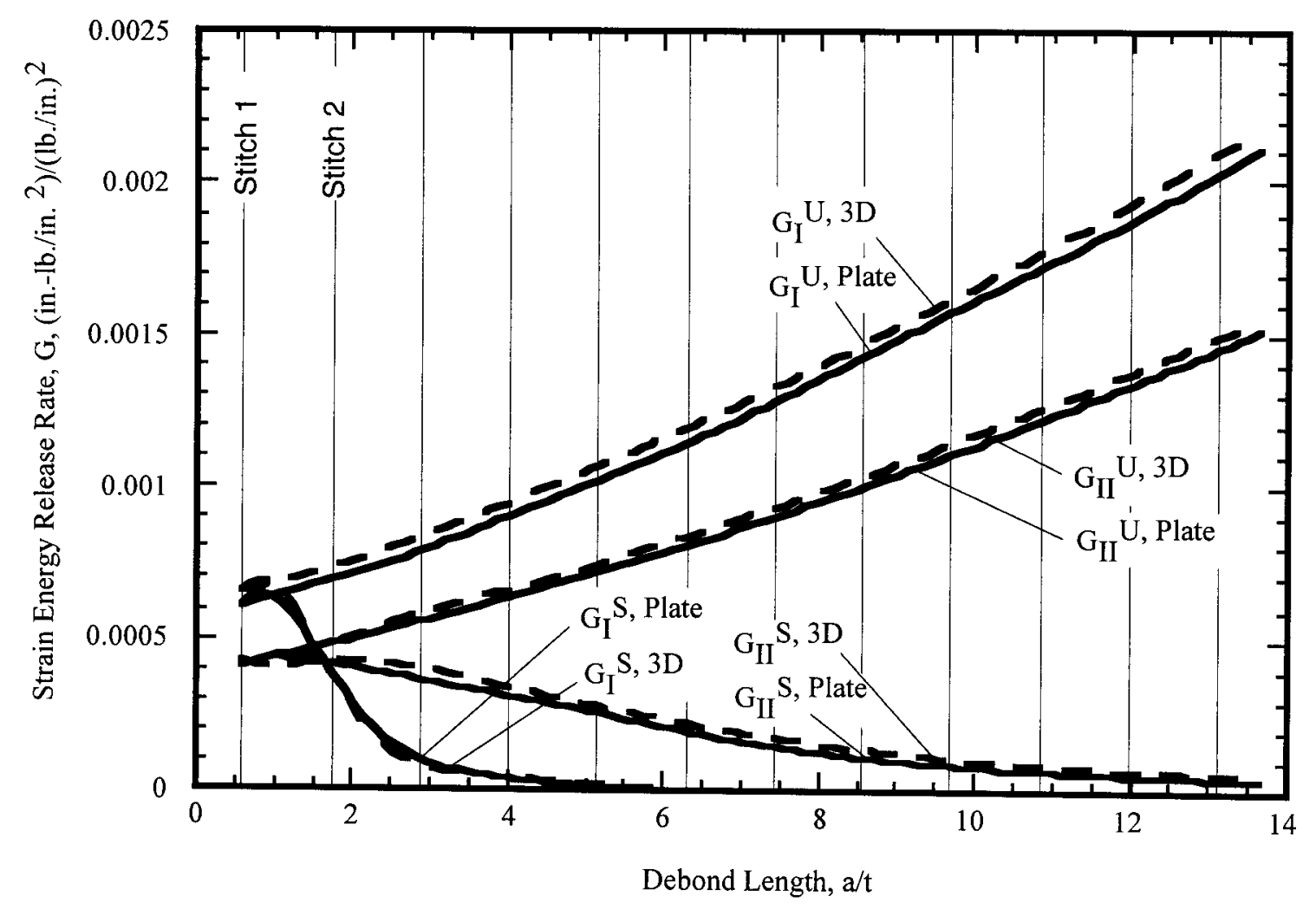

(b) Debond configurations with thickness, $1 / 2 t=18.2$

Figure 7. Strain energy release rates. 


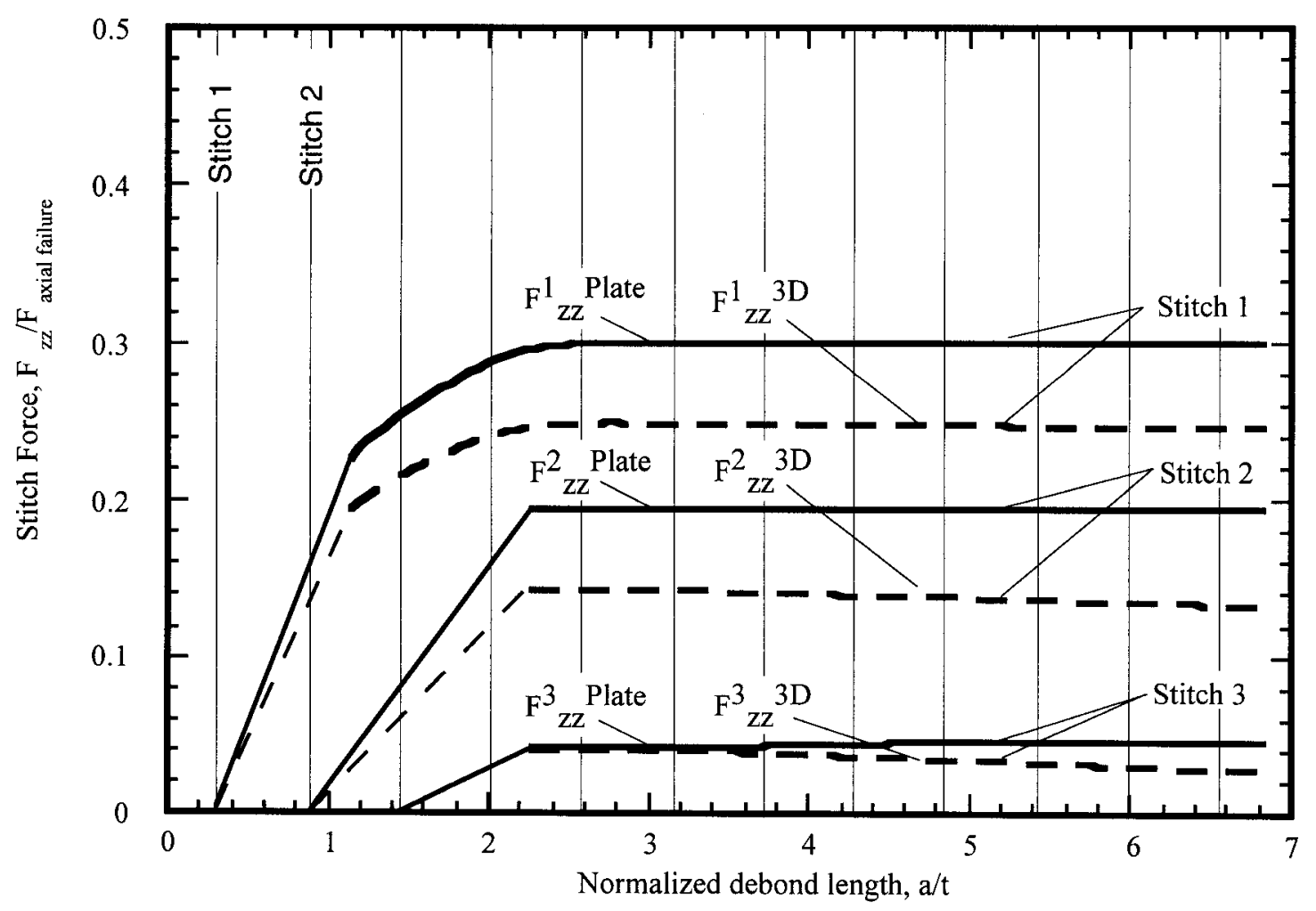

(a) Axial forces for $1 / 2 t=9.09$

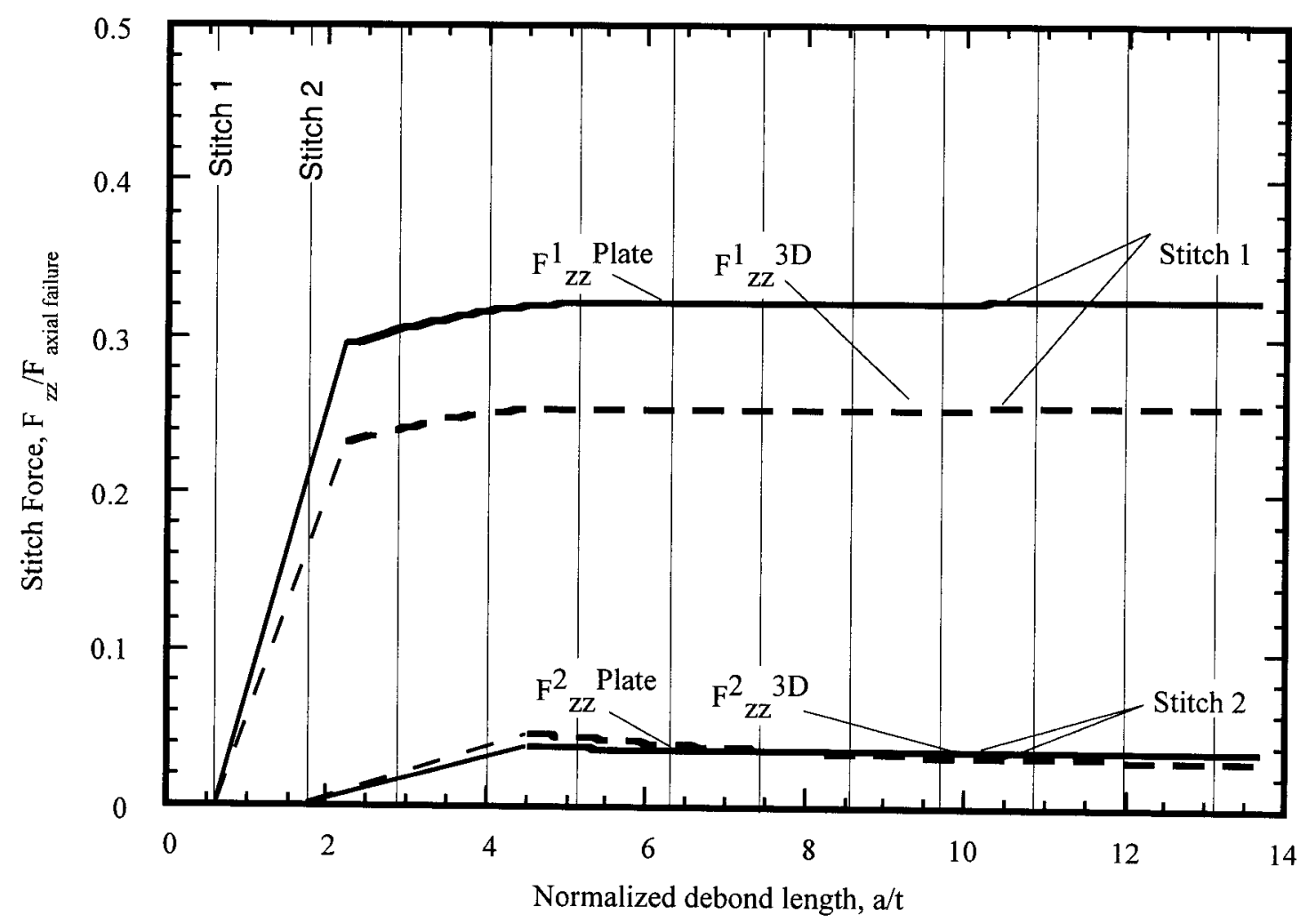

(b) Axial forces for $/ / 2 t=18.2$

Figure 8. Stitch force. 


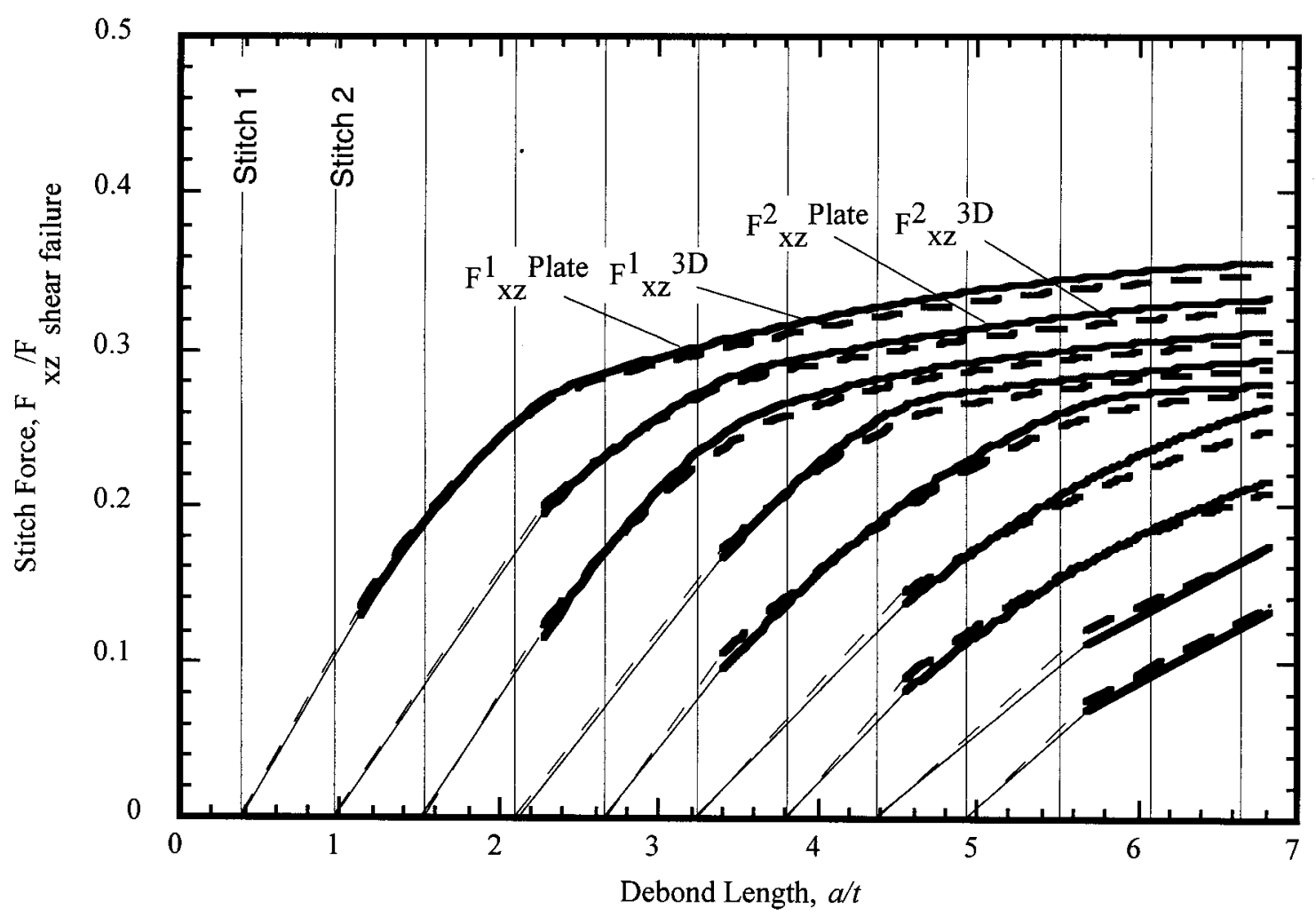

(c) Longitudinal shear forces for $1 / 2 t=9.09$

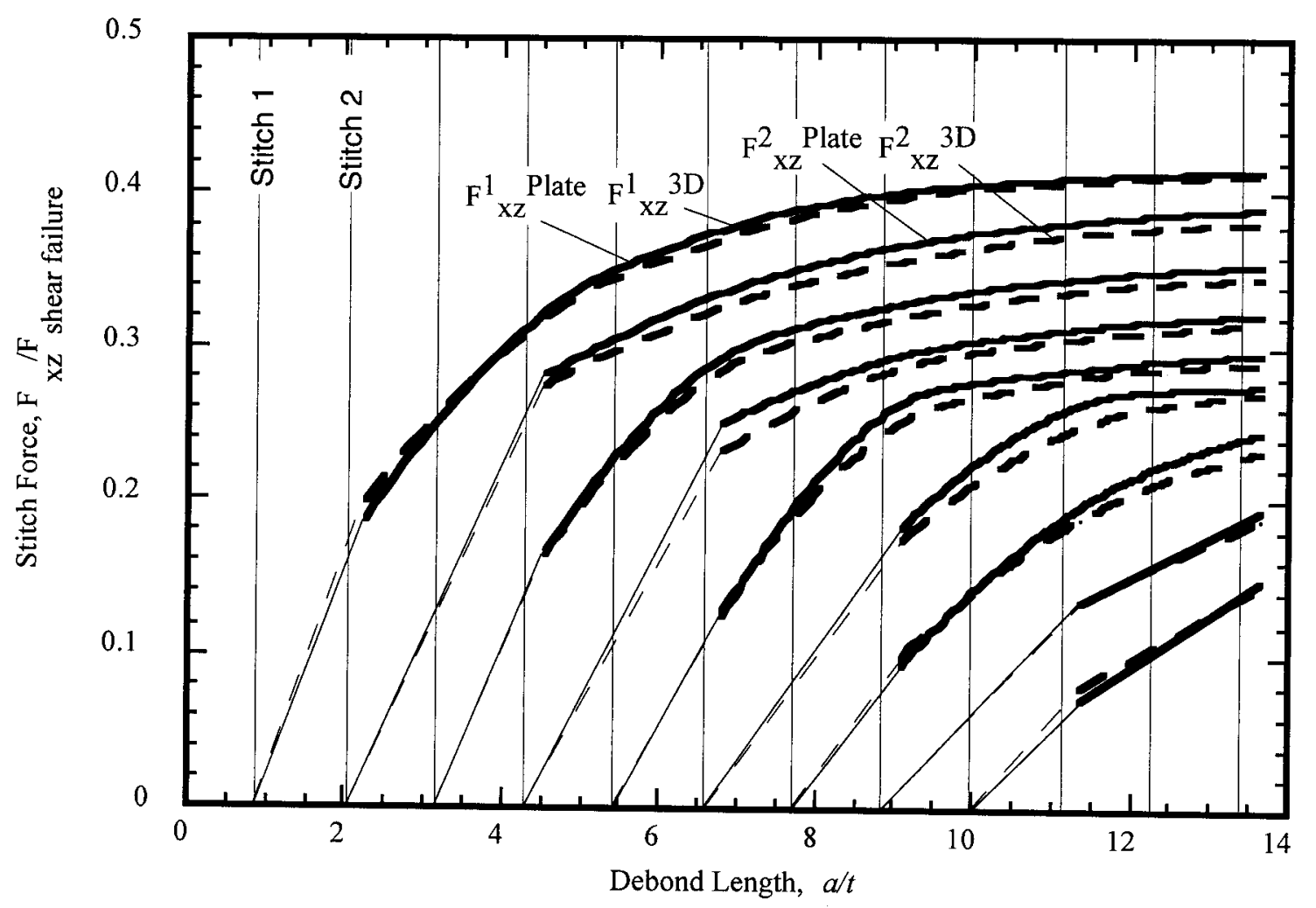

(d) Longitudinal shear forces for $1 / 2 t=18.2$

Figure 8. Stitch force (concluded). 


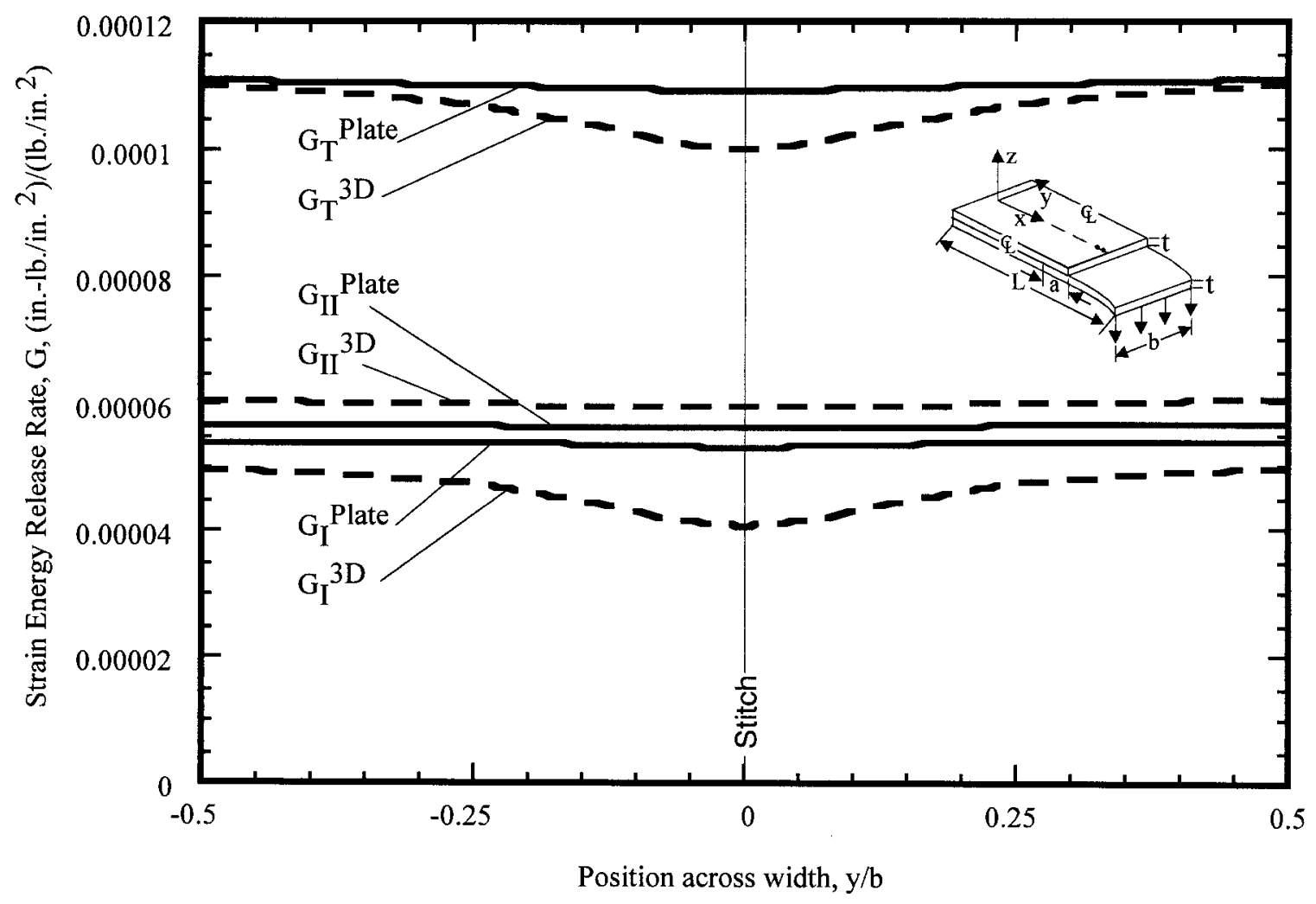

(a) Debond configuration with thickness, $1 / 2 t=9.09$, a/t=1.14

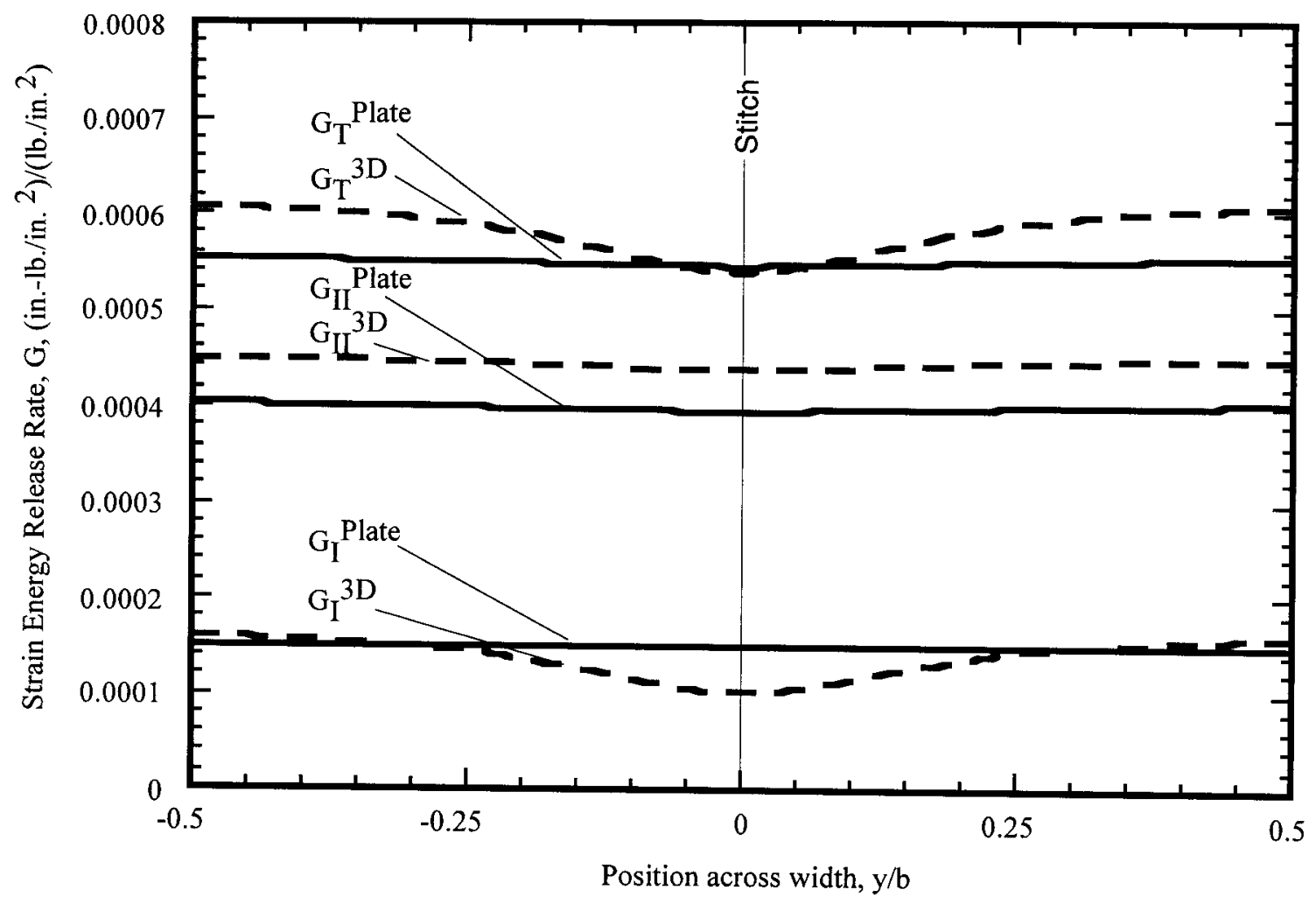

(b) Debond configuration with thickness, $1 / 2 t=18.2$, a/t=2.27

Figure 9. Strain energy release rate distribution. 


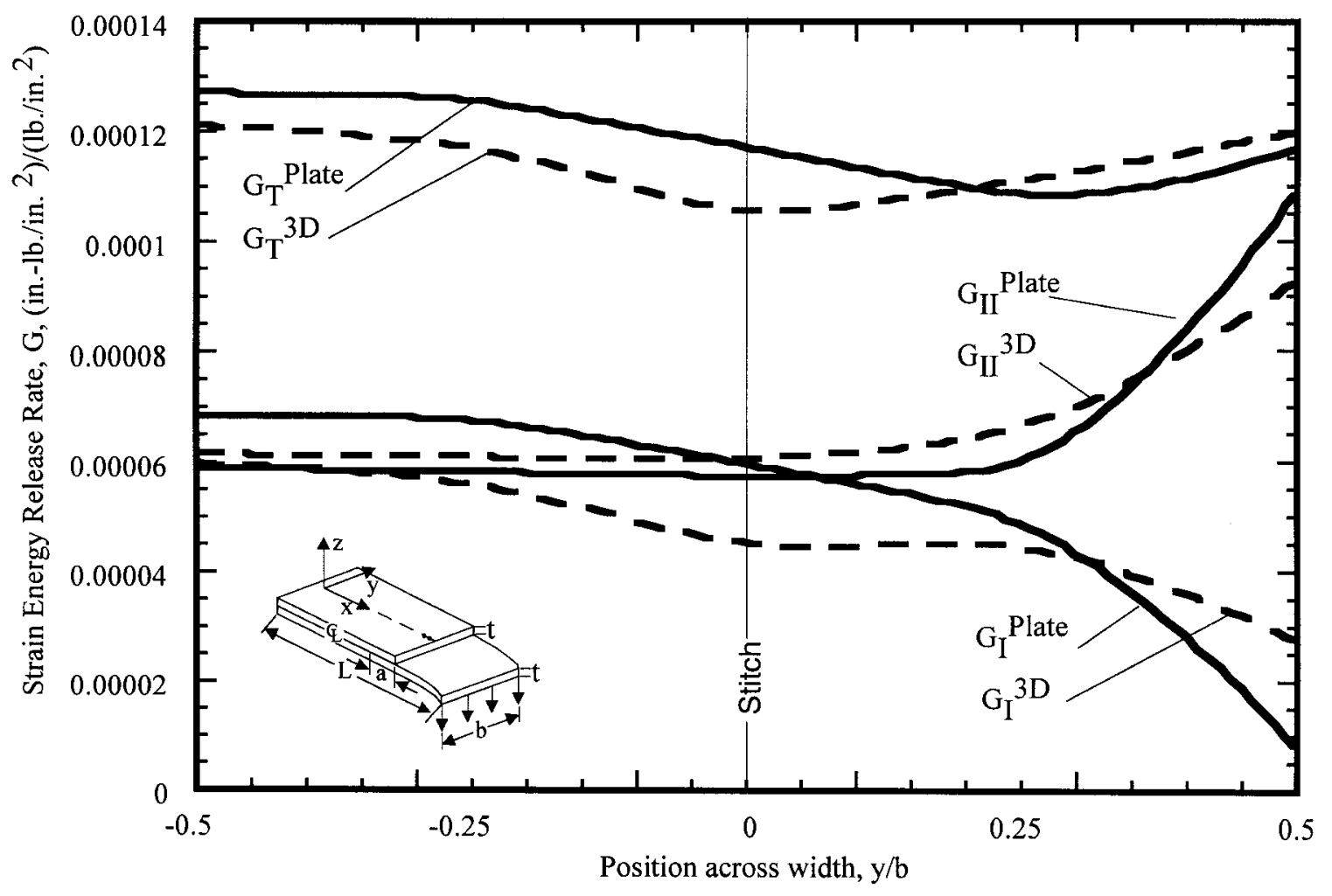

(a) Debond configurations with thickness, $1 / 2 t=9.09$, $a / t=1.14$

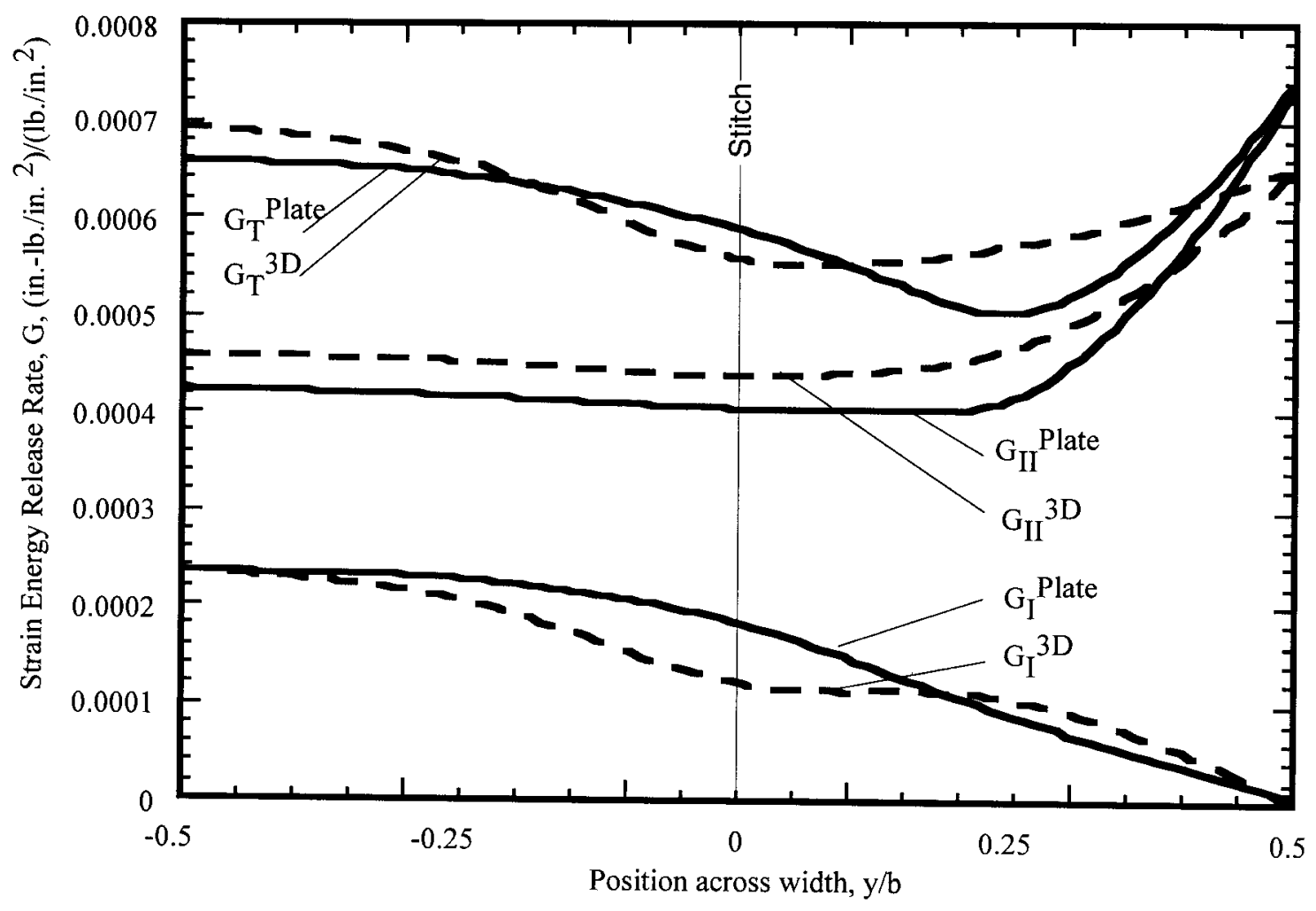

(b) Debond configurations with thickness, $1 / 2 t=18.2$, a/t=2.27

Figure 10. Strain energy release rate distribution. 


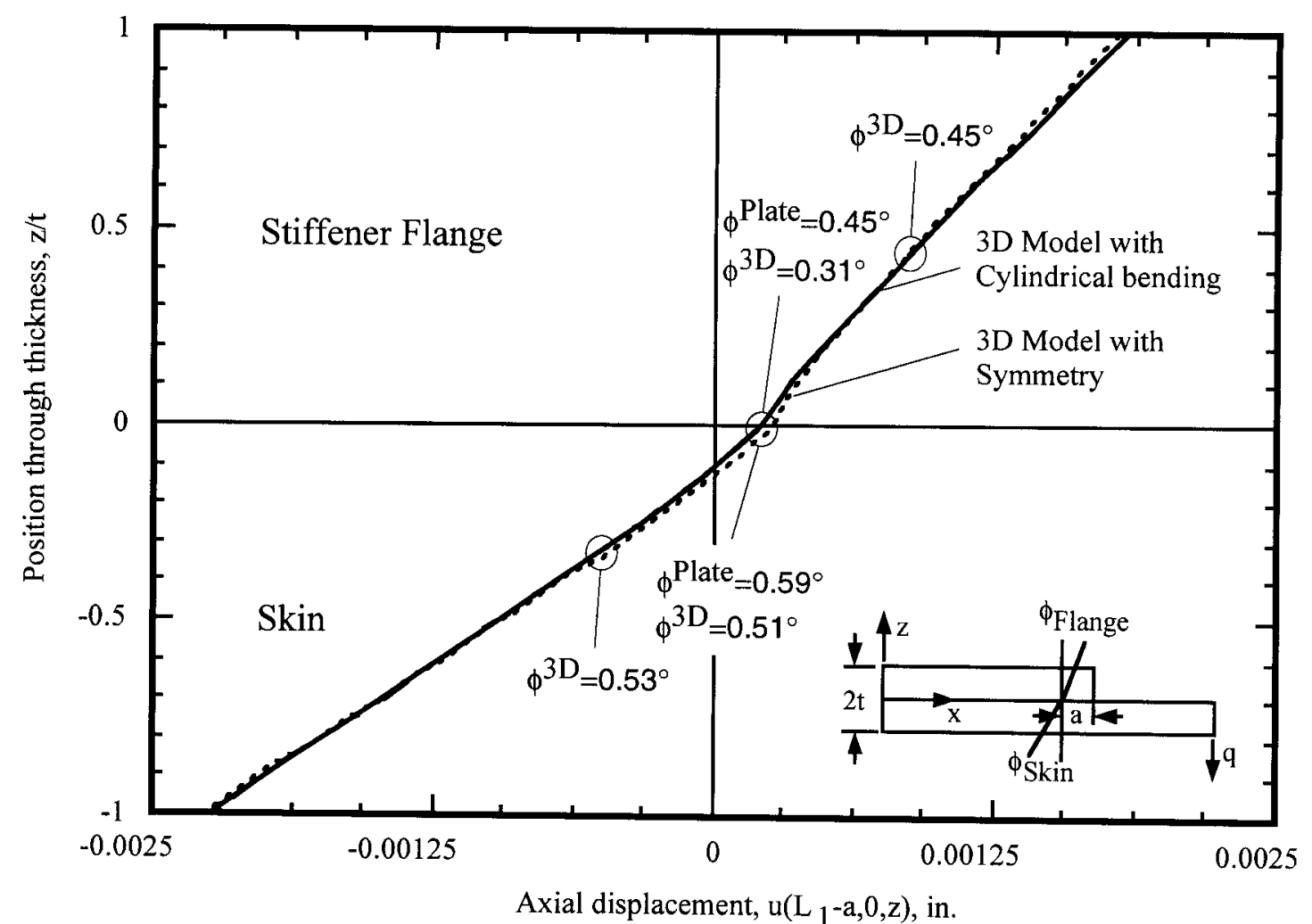

(a) Axial deformation for $1 / 2 t=9.09$, a/t=1.14

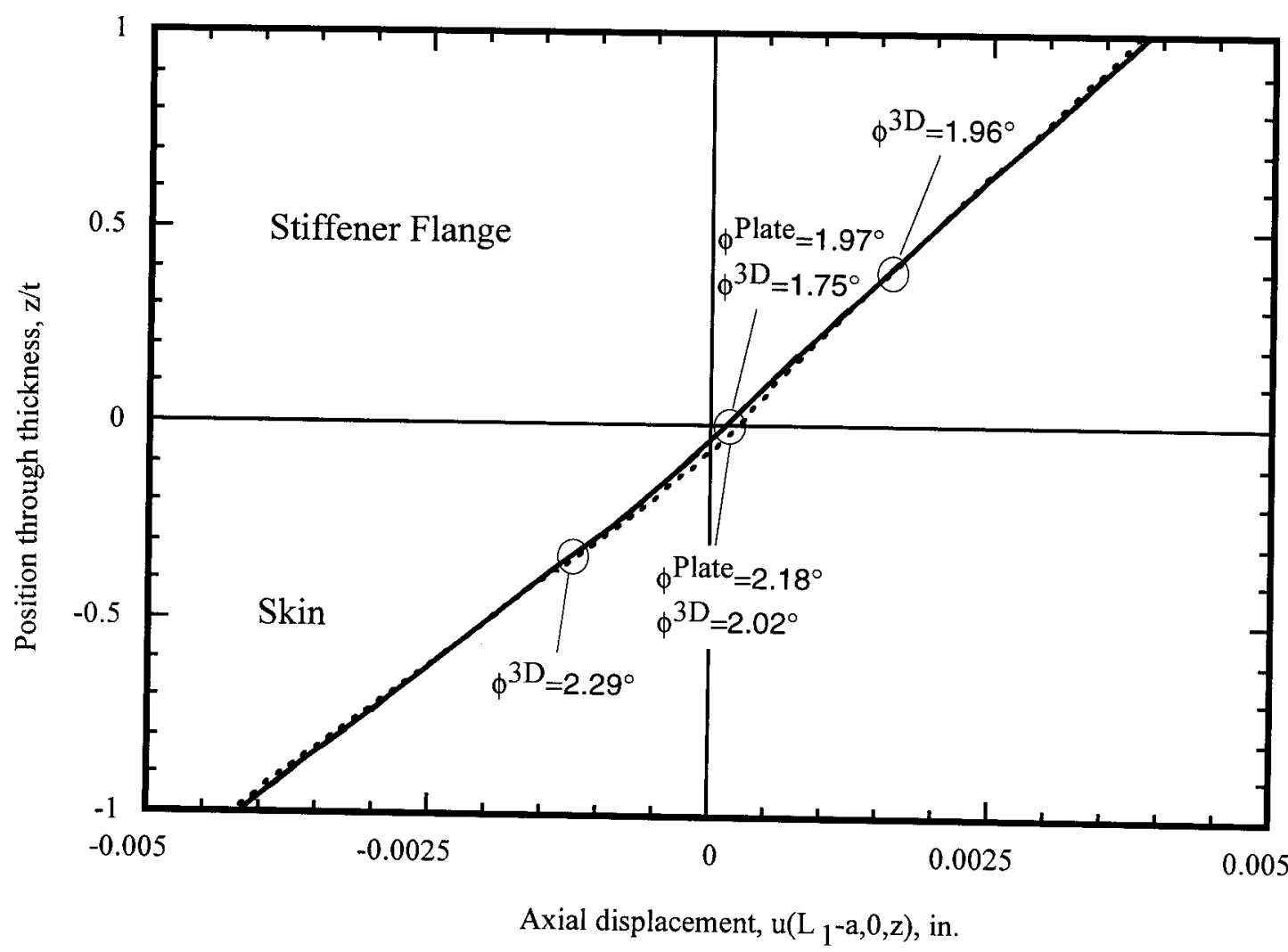

(b) Axial deformation for $1 / 2 t=18.2$, a/t=2.27

Figure 11. Axial deformation at the debond front . 